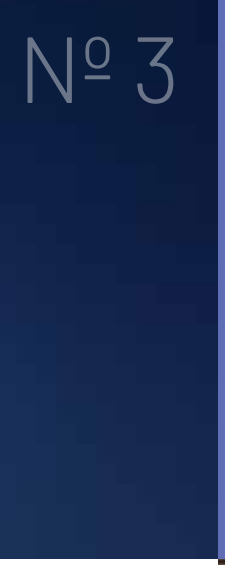

\title{
El desafío social en tiempos del COVID-19
}
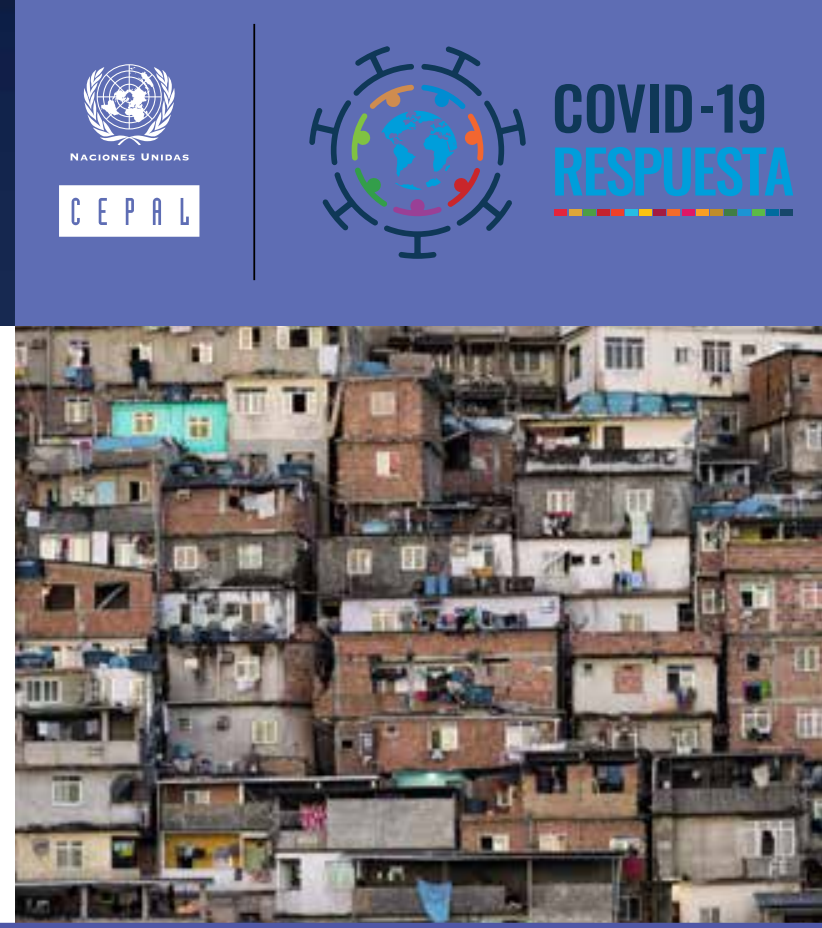

A. La pobreza, la pobreza extrema y la desigualdad aumentarán en todos los países de la región

- La pandemia del COVID-19 tiene fuertes efectos en el ámbito de la salud y profundas implicaciones sobre el crecimiento económico y el desarrollo social. Llega a América Latina y el Caribe en un contexto de bajo crecimiento -como fue analizado en anteriores informes especiales sobre la materia (CEPAL, 2020a y 2020b) - y, sobre todo, de alta desigualdad y vulnerabilidad, en el que se observan tendencias crecientes en la pobreza y pobreza extrema, un debilitamiento de la cohesión social y manifestaciones de descontento popular.

- Las medidas de cuarentena y distanciamiento físico, necesarias para frenar la propagación acelerada del coronavirus y salvar vidas, generan pérdidas de empleo (en 2020 habría 11,6 millones de desocupados más que en 2019) y reducen los ingresos laborales de las personas y de los hogares. La pérdida de ingresos afecta sobre todo a los amplios estratos de población que se encuentran en situación de pobreza y vulnerabilidad, así como a las personas que trabajan en actividades más expuestas a despidos y reducciones salariales y, en general, en condiciones de precariedad laboral.

- En la región, los mercados laborales suelen ser precarios: existe una alta proporción de empleos informales (un 53,1\% en 2016, según la Organización Internacional del Trabajo (OIT, 2018)). En 2018 solo el $47,4 \%$ de los ocupados aportaba al sistema de pensiones y más de $20 \%$ de los ocupados vivía en la pobreza. Las mujeres, las jóvenes, los indígenas, los afrodescendientes y los migrantes están sobrerrepresentados entre los trabajadores informales.

\section{Índice}

A. La pobreza, la pobreza extrema y la desigualdad aumentarán en todos los países de la región 1

B. Grupos especialmente vulnerables a la crisis socioeconómica.

C. Medidas emergentes y reforzamiento de las medidas existentes de protección social.

D. Un ingreso básico para satisfacer necesidades y sostener el consumo

E. El desafío es fortalecer el Estado de bienestar para evitar otra década perdida.

Bibliografía .21

Anexo 


\section{Evolución de la pobreza y la pobreza extrema}

- Ante la caída del 5,3\% del PIB y el aumento del desempleo de 3,4 puntos porcentuales proyectados por la Comisión Económica para América Latina y el Caribe (CEPAL) en el Informe Especial COVID-19, $\mathrm{N}^{\circ}$ 2, en 2020 la pobreza en América Latina aumentaría al menos $\mathbf{4 , 4}$ puntos porcentuales $\mathbf{( 2 8 , 7}$ millones de personas adicionales) con respecto al año previo, por lo que alcanzaría a un total de 214,7 millones de personas (el 34,7\% de la población de la región) (CEPAL, 2020b). Entre estas personas, la pobreza extrema aumentaría 2,6 puntos porcentuales (15,9 millones de personas adicionales) y llegaría a afectar a un total de 83,4 millones de personas.

- Este aumento de la pobreza y la pobreza extrema compromete gravemente la posibilidad de poner fin a la pobreza en todas sus formas y en todo el mundo en 2030 (Objetivo de Desarrollo Sostenible 1) y más ampliamente el logro de todas las metas de la dimensión social de la Agenda 2030 para el Desarrollo Sostenible.

- Los efectos de la pandemia sobre el PIB y el empleo son diferentes según los países, por lo que la magnitud de los incrementos de la pobreza y la pobreza extrema proyectados también varía. Dada la incertidumbre del contexto actual y su evolución, en el cuadro 1 se presentan tres escenarios (bajo, medio y alto) de la evolución de la pobreza y la pobreza extrema en 17 países de la región. En el escenario medio, la pobreza aumentaría 4,4 puntos porcentuales; en el escenario bajo, 3,4 puntos porcentuales, y en el alto, 5,5 puntos porcentuales.

Cuadro 1 | América Latina (17 países): proyección de la población en situación de pobreza extrema y pobreza en 2020, sin considerar el efecto de las medidas anunciadas para mitigar el impacto del COVID-19

(En porcentajes)

\begin{tabular}{|c|c|c|c|c|c|c|c|c|}
\hline \multirow{3}{*}{ País } & \multicolumn{4}{|c|}{ Pobreza extrema } & \multicolumn{4}{|c|}{ Pobreza } \\
\hline & \multirow{2}{*}{$\frac{2019^{a}}{\text { Nivel }}$} & \multicolumn{3}{|c|}{$2020^{b}$} & \multirow{2}{*}{$\begin{array}{l}2019^{a} \\
\text { Nivel }\end{array}$} & \multicolumn{3}{|c|}{$2020^{b}$} \\
\hline & & $\begin{array}{l}\text { Escenario } \\
\text { bajo }\end{array}$ & $\begin{array}{l}\text { Escenario } \\
\text { medio }\end{array}$ & $\begin{array}{l}\text { Escenario } \\
\text { alto }\end{array}$ & & $\begin{array}{l}\text { Escenario } \\
\text { bajo }\end{array}$ & $\begin{array}{l}\text { Escenario } \\
\text { medio }\end{array}$ & $\begin{array}{l}\text { Escenario } \\
\text { alto }\end{array}$ \\
\hline Argentinac $^{c}$ & 3,8 & 5,1 & 5,5 & 6,3 & 26,7 & 32,5 & 33,6 & 35,3 \\
\hline $\begin{array}{l}\text { Bolivia (Estado } \\
\text { Plurinacional de) }\end{array}$ & 14,3 & 15,4 & 16,0 & 16,7 & 32,3 & 33,6 & 34,4 & 35,5 \\
\hline Brasil & 5,4 & 6,9 & 7,4 & 7,9 & 19,4 & 23,0 & 24,3 & 25,4 \\
\hline Chile & 1,4 & 2,1 & 2,3 & 2,6 & 9,8 & 11,9 & 12,7 & 13,7 \\
\hline Colombia & 10,3 & 11,3 & 12,0 & 12,7 & 29,0 & 30,4 & 31,5 & 32,5 \\
\hline Costa Rica & 4,0 & 4,7 & 4,9 & 5,3 & 16,0 & 17,7 & 18,4 & 19,1 \\
\hline Ecuador & 7,6 & 9,9 & 10,7 & 11,6 & 25,7 & 30,0 & 30,8 & 31,9 \\
\hline El Salvador & 7,4 & 8,5 & 9,0 & 9,6 & 33,7 & 35,4 & 36,4 & 37,3 \\
\hline Guatemala & 19,8 & 21,2 & 21,4 & 21,8 & 48,6 & 50,3 & 50,5 & 50,9 \\
\hline Honduras & 18,7 & 19,5 & 19,8 & 20,5 & 54,8 & 56,3 & 57,1 & 57,8 \\
\hline México & 11,1 & 14,9 & 15,9 & 17,1 & 41,9 & 46,7 & 47,8 & 48,9 \\
\hline Nicaragua & 18,0 & 20,7 & 21,3 & 22,2 & 47,1 & 50,6 & 51,6 & 52,7 \\
\hline Panamá & 6,2 & 6,4 & 6,6 & 6,8 & 14,2 & 14,5 & 14,9 & 15,6 \\
\hline Paraguay & 6,2 & 6,3 & 6,5 & 6,9 & 19,4 & 19,8 & 20,3 & 21,1 \\
\hline Perú & 3,7 & 4,6 & 4,8 & 5,1 & 16,5 & 18,5 & 19,1 & 20,1 \\
\hline $\begin{array}{l}\text { República } \\
\text { Dominicana }\end{array}$ & 4,5 & 4,6 & 4,9 & 5,3 & 20,3 & 20,7 & 21,1 & 21,7 \\
\hline Uruguay & 0,1 & 0,2 & 0,3 & 0,4 & 2,9 & 4,2 & 4,8 & 5,7 \\
\hline América Latina ${ }^{d}$ & 11,0 & 13,0 & 13,5 & 14,2 & 30,3 & 33,7 & 34,7 & 35,8 \\
\hline
\end{tabular}

Fuente: Comisión Económica para América Latina y el Caribe (CEPAL), sobre la base del Banco de Datos de Encuestas de Hogares (BADEHOG).

a Proyecciones.

b Proyecciones preliminares basadas en supuestos de impacto sobre el empleo y los ingresos laborales para los distintos sectores productivos. Los tres escenarios se diferencian según la variación del ingreso medio de los hogares sea menor a la variación del PIB (escenario bajo), igual (escenario medio) o mayor (escenario alto).

Corresponde a áreas urbanas.

d Corresponde a los 17 países incluidos en el cuadro más la República Bolivariana de Venezuela. 
- De esa información se desprenden cuatro conclusiones:

i) En todos los escenarios, la pobreza y la pobreza extrema aumentarían en todos los países.

ii) En el escenario alto, los mayores aumentos de la pobreza extrema se darían en México, Nicaragua y el Ecuador.

iii) También en el escenario alto, la pobreza en general aumentaría especialmente en la Argentina, México, el Ecuador y el Brasil.

iv) Resalta la particular vulnerabilidad de las tres mayores economías de la región.

- El impacto hasta aquí descrito considera únicamente las consecuencias de la pandemia en el mercado laboral y la pérdida de ingresos asociada. En caso de reducirse las remesas provenientes de familiares que migraron, se acentuará la situación de pobreza de quienes las reciben en sus países de origen (véase el gráfico 1). Esta reducción es probable ante el fuerte impacto del COVID-19 en la región y en países extrarregionales receptores de migrantes latinoamericanos y caribeños, como los Estados Unidos y España.

Gráfico 1 | América Latina (13 países): tasa de pobreza sin remesas para los hogares receptores de remesas, totales nacionales, alrededor de 2017

(En porcentajes)

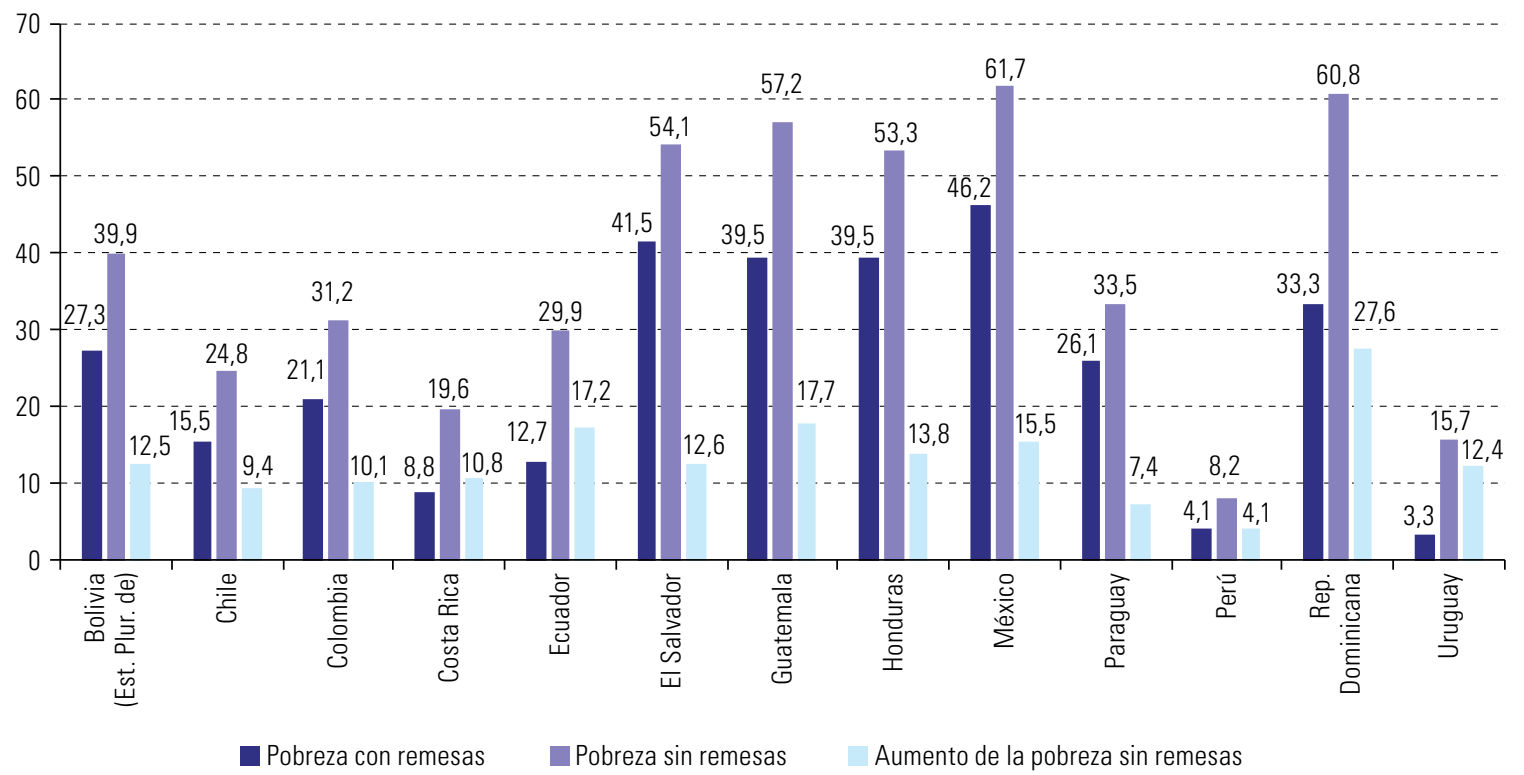

Fuente: Comisión Económica para América Latina y el Caribe (CEPAL), Panorama Social de América Latina, 2019(LC/PUB.2019/22-P/Rev.1), Santiago.

- En línea con el aumento de la pobreza y la pobreza extrema, también aumentará la desigualdad en todos los países de la región. La CEPAL proyecta incrementos del índice de Gini de entre el $\mathbf{0 , 5} \%$ y el $\mathbf{6 , 0} \%$. Una vez más, los peores resultados se esperan en las economías más grandes de la región (véase el cuadro 2). Esto representa un retroceso respecto a los esfuerzos de la región en la década de 2000, cuando por primera vez en su historia se cambió la tendencia de la desigualdad y se aprendió que avanzar en la igualdad tenía resultados muy positivos en la lucha contra la pobreza.

- En este escenario de mayor pobreza y desigualdad, amplios estratos de la población de la región viven en condiciones crónicas de inseguridad económica y son muy vulnerables ante las pérdidas de ingresos laborales. En 2019, el 77\% de la población de la región (470 millones de personas) pertenecía a los estratos de ingresos bajos o medios-bajos, sus ingresos per cápita eran de hasta tres veces la línea de pobreza (véase el gráfico 2) y no contaban con ahorros suficientes para enfrentar una crisis. En 2017, solo el 31,8\% de las personas económicamente activas que vivían en hogares de los estratos de ingresos bajos y medios-bajos estaban afiliadas o cotizaban en el sistema de pensiones. 
Cuadro 2 I América Latina (17 países): variación proyectada del índice de Gini en 2020, sin considerar el efecto de las medidas anunciadas para mitigar el impacto del COVID-19

\begin{tabular}{ll}
\hline Entre el $\mathbf{0 , 5} \%$ y el $\mathbf{1 , 4 \%}$ & Guatemala \\
& Honduras \\
& Panamá \\
& Paraguay \\
& República Dominicana \\
\hline Entre el $\mathbf{1 , 5 \%}$ y el $\mathbf{2 , 9 \%}$ & Bolivia (Estado Plurinacional de) \\
& Chile \\
& Colombia \\
& Costa Rica \\
& El Salvador \\
Nicaragua \\
Perú \\
\hline $3,0 \%$ o más & Argentina \\
Brasil \\
Ecuador \\
México \\
\hline Uruguay
\end{tabular}

Fuente: Comisión Económica para América Latina y el Caribe (CEPAL), sobre la base del Banco de Datos de Encuestas de Hogares (BADEHOG).

n Teniendo en cuenta la previsión de caída del PIB regional (5,3\%) y el aumento del desempleo por los efectos de la pandemia, la CEPAL estima que alrededor del $\mathbf{1 0} \%$ de las personas que se encontraban en situación de pobreza no extrema en 2019 (11,8 millones de personas) verían deteriorada su situación económica y caerían en una situación de pobreza extrema (véase el gráfico 2). Asimismo, el $15 \%$ de las personas que pertenecían a estratos bajos no pobres (entre 1 y 1,8 líneas de pobreza per cápita) caerían en la pobreza no extrema (20,8 millones de personas) o en la pobreza extrema (3 millones de personas).

- También habría un fuerte deterioro de la posición de las personas que pertenecían a los estratos medios, aunque los impactos —estimados como movilidad económica descendente entre estratos- disminuyen a medida que se avanza en la escala social. En este grupo, los estratos medios-bajos serían los más afectados. Se deterioraría la situación económica de al menos un 15\% de estas personas: 16,7 millones pasarían a pertenecer a estratos de bajos ingresos, pero aún fuera de la pobreza, en tanto que 2,5 millones quedarían en situación de pobreza, principalmente no extrema. Los estratos intermedios sufrirían un deterioro menor, ya que solo el $11 \%$ de las personas pasarían a estratos inferiores (10,7 millones), quedando en su mayoría en el estrato medio-bajo (9,1 millones).

- Los estratos medios-altos y altos serían los menos afectados, con deterioros económicos que en su mayoría los llevarían al estrato inmediatamente inferior. Sin embargo, una pequeña proporción de las personas de estos estratos caería —al menos temporalmente- en situaciones de pobreza o pobreza extrema, en función de la disminución de sus ingresos corrientes.

- Aunque las personas pertenecientes a los estratos medios-altos y altos pueden recurrir a la liquidación de activos para sostener, aun a corto plazo, sus condiciones de vida, hay una proporción considerable de hogares (principalmente a medida que se desciende en la escala social) que mantiene sus condiciones de vida sobre la base del endeudamiento, por lo que una caída significativa de sus ingresos podría provocar sobreendeudamiento y la pérdida posterior de sus activos. 
Gráfico 2 | América Latina (18 paísesª): nivel y evolución de la población según estratos de ingreso per cápitab, 2019 y 2020

(En millones de personas)

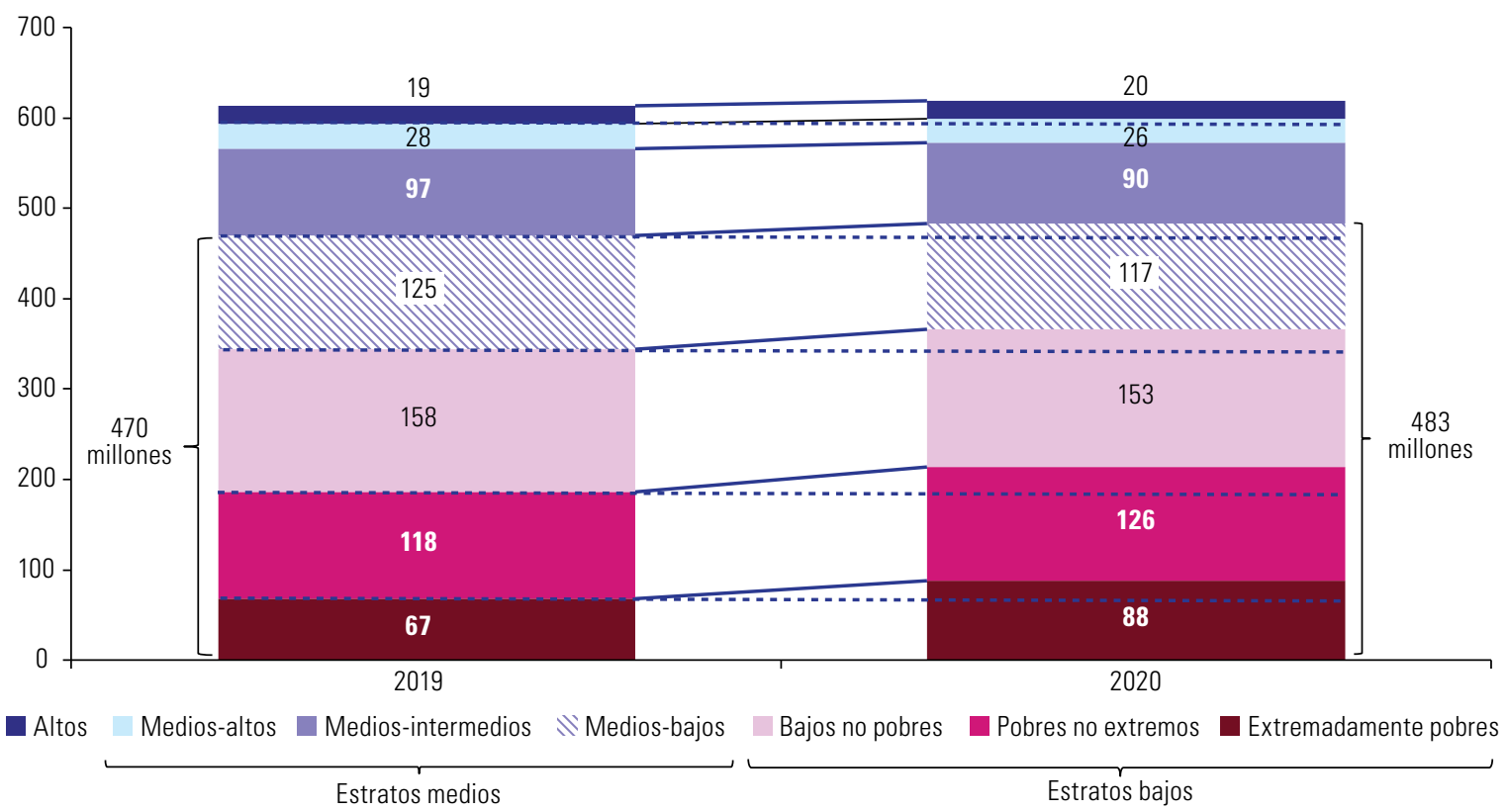

Fuente: Comisión Económica para América Latina y el Caribe (CEPAL), sobre la base del Banco de Datos de Encuestas de Hogares (BADEHOG).

a Los países considerados son: Argentina, Bolivia (Estado Plurinacional de), Brasil, Chile, Colombia, Costa Rica, Ecuador, El Salvador, Guatemala, Honduras, México, Nicaragua, Panamá, Paraguay, Perú, República Dominicana, Uruguay y Venezuela (República Bolivariana de).

Los datos para 2019 corresponden a una proyección basada en una caída del 5,3\% del PIB y un aumento del desempleo en 3,4 puntos porcentuales.

b Límites de los ingresos per cápita de los estratos: "extremadamente pobres" se refiere a ingresos inferiores a 1 línea de extrema pobreza; "pobres no extremos", desde 1 línea de extrema pobreza y por debajo de 1 línea de pobreza; "bajos no pobres", desde 1 línea de pobreza y por debajo de 1,8 líneas de pobreza; "medios-bajos", entre 1,8 y 3 líneas de pobreza; "medios-intermedios", por encima de 3 líneas de pobreza y hasta 6 líneas de pobreza; "medios-altos", por encima de 6 líneas de pobreza y hasta 10 líneas de pobreza, y "altos", por encima de 10 líneas de pobreza.

\section{B. Grupos especialmente vulnerables a la crisis socioeconómica}

- La pandemia tiene un impacto discriminado en diversos grupos de población y su capacidad de respuesta. La imposibilidad de trabajar desde el domicilio, las condiciones de hacinamiento y la falta de acceso a agua y saneamiento aumentan el riesgo de infección de la población en situación de pobreza y vulnerabilidad. Asimismo, su riesgo de muerte es mayor por la mayor incidencia de condiciones preexistentes de salud como enfermedades pulmonares, cardiovasculares y diabetes y por carecer de acceso adecuado a la atención médica.

- Los diferentes impactos socioeconómicos reflejan la matriz de la desigualdad social en la región, cuyos ejes estructurantes son la pertenencia a distintos estratos socioeconómicos o clases sociales, el género, la etapa del ciclo de vida, la condición étnico-racial y el territorio, a lo que se suman otros factores como la condición de discapacidad, el estatus migratorio o la situación de calle. Estas desigualdades se acumulan, se potencian e interactúan entre sí, causando múltiples discriminaciones que conllevan diferencias en el ejercicio de los derechos.

- Las medidas de protección social de corto, mediano y largo plazo para enfrentar los efectos de la pandemia deben considerar el bienestar de toda la población, especialmente el de los grupos que experimentan múltiples formas de exclusión y sufren más agudamente los impactos de la crisis (véase el cuadro 3). Por ello, la protección social y el bienestar deben ser vistos con una perspectiva de universalismo sensible a las diferencias, es decir, teniendo en cuenta las necesidades, carencias y discriminaciones de grupos específicos.

- Los grupos más afectados abarcan una gran proporción de la población de los países de la región. Por ejemplo, en el caso del Brasil, las estimaciones realizadas por la Institución Fiscal Independente (IFI), órgano del Senado de dicho país, con información hasta el 1 de mayo de 2020 indican que la mitad de la población (111 millones de personas) podría requerir ayuda económica para enfrentar los efectos de la pandemia, lo que supondría un costo de más de 37.000 millones de dólares. Esto implicaría duplicar con creces el alcance de las medidas en curso, que llegan a unos 50 millones de personas con un costo de 17.000 millones de dólares (Folha de S. Paulo, 2020). 
Cuadro 3 | Poblaciones más afectadas por los impactos socioeconómicos del COVID-19

\begin{tabular}{ll}
\hline Poblaciones & Ámbitos en que incide la pandemia \\
\hline Mujeres & Salud física y mental \\
Estratos de ingresos bajos y medios-bajos & Nutrición \\
Trabajadores informales & Educación \\
Trabajadoras domésticas remuneradas & Ingresos laborales \\
Niños, niñas y adolescentes & Trabajo infantil \\
Jóvenes & Acceso a servicios básicos (agua, saneamiento, \\
Personas mayores & electricidad, gas, tecnologías digitales) \\
Población rural & Trabajo de cuidado no remunerado \\
Pueblos indígenas & Violencia intrafamiliar \\
Afrodescendientes & \\
Personas con discapacidad & \\
Migrantes & \\
Personas en situación de calle & \\
\hline
\end{tabular}

Fuente: Comisión Económica para América Latina y el Caribe (CEPAL).

- Si bien la crisis afecta a toda la fuerza de trabajo, la situación de los trabajadores informales de ambos sexos, y especialmente la de las mujeres y las personas jóvenes, indígenas, afrodescendientes y migrantes resulta de la confluencia de los ejes de la desigualdad y constituye un fuerte núcleo de vulnerabilidad. La gran mayoría de estos trabajadores no disponen de ahorros suficientes para enfrentar la crisis en un escenario en que, además, las remesas también pueden sufrir una fuerte contracción.

- Las medidas de distanciamiento físico les impiden desarrollar sus actividades y generar ingresos que les permitan mantenerse fuera de la pobreza. Al contar con un escaso o nulo acceso a la seguridad social, su capacidad para beneficiarse del seguro de desempleo o acceder a la atención de salud queda considerablemente restringida, una situación en la que se encuentran la mayoría de estas personas. Cabe señalar que solo ocho países latinoamericanos y tres caribeños cuentan con seguro de desempleo.

- El incremento del trabajo informal ante el aumento del desempleo dificultará que esos trabajadores y sus familias accedan a ingresos para sostener un nivel de vida digno. Esta situación presionará además la sostenibilidad financiera de los sistemas de protección social por la disminución de los aportes directos y las posibles reducciones de cobertura.

- Las mujeres se encuentran en una situación particularmente vulnerable. Al contar con una inserción laboral en condiciones de mayor precariedad y una mayor representación en el trabajo informal (en 2016 esta era del 54,3\%, frente al 52,3\% en el caso de los hombres (OIT, 2018)), están más expuestas al riesgo de desempleo. Las trabajadoras domésticas remuneradas (el $11,4 \%$ de las mujeres ocupadas), muchas de ellas migrantes, indígenas o afrodescendientes, se encuentran en una situación particularmente compleja. Pocas tienen acceso a la seguridad social, y están más desprotegidas en escenarios de desempleo sostenido. Al no poder trabajar a distancia, los ajustes de los presupuestos de las familias empleadoras aumentan la incertidumbre de su remuneración, sobre todo en el caso - frecuente- de no contar con un contrato formal.

- En un contexto de confinamiento, cierre de escuelas y necesidad de cuidados ante la posible presencia de uno o más contagiados en el hogar, la carga de trabajo doméstico no remunerado que asumen las mujeres, las adolescentes y las niñas, así como los casos de violencia hacia ellas, se incrementan significativamente.

- Los niños, niñas y adolescentes se han visto afectados por el cierre de las escuelas. Al 27 de abril de 2020, 35 países de la región habían decidido suspender las clases en todos los niveles educativos, lo que ha afectado a más de 115 millones de alumnos desde el nivel preescolar hasta el terciario (UNESCO, 2020). Si bien 21 de esos países han establecido formas de continuidad de los estudios a distancia, esto puede acentuar las brechas de aprendizaje entre los alumnos de las escuelas públicas y las privadas, en detrimento de la población de menores recursos. Esta tiene un acceso limitado o nulo a dispositivos tecnológicos e Internet, vive en condiciones de hacinamiento y los adultos presentan menores niveles educativos. Si el período 
de suspensión es muy largo, aumentará el riesgo de abandono escolar, particularmente para los afectados por la caída drástica de los ingresos familiares. Aumenta también el riesgo para la salud mental de los niños, niñas y adolescentes a raíz del confinamiento y el estrés familiar.

- El sano desarrollo de los niños, niñas y adolescentes está en peligro. Si no se mantienen los programas de alimentación escolar se deteriorará la nutrición y alimentación de la población estudiantil de los sectores más vulnerables. El incremento de la desnutrición infantil y la malnutrición por exceso de peso son riesgos críticos que se deben prevenir.

- Es probable que los hijos de las familias más pobres se vean obligados a entrar en el mercado de trabajo, lo que incrementaría las tasas de trabajo infantil (que corresponden al 7,3\% de los niños de 5 a 17 años, unos 10,5 millones de niños (OIT,2018)). En el caso de las niñas y las adolescentes se debe agregar el posible aumento de la carga de trabajo doméstico y de cuidado no remunerado.

- En una situación de aumento del desempleo y restricción de los presupuestos familiares, la población joven enfrentará un escenario más adverso respecto de sus oportunidades de continuidad educativa e inserción laboral, lo que impactará en sus trayectorias de inclusión social y laboral, especialmente entre aquellos que pertenecen a los estratos de ingresos bajos. Esto reviste una especial gravedad en aquellos países cuya tasa de desempleo juvenil es estructuralmente mucho mayor que la del promedio de la economía.

- Las personas mayores de $\mathbf{6 0}$ años, es decir, cerca del 13\% de la población de la región (85 millones de personas), enfrentan una mortalidad más alta en la pandemia; por tanto, su demanda de atención especializada y crítica de salud es mayor. Asimismo, el aislamiento en que viven muchas de ellas limita su capacidad para responder a la enfermedad, genera riesgos para su seguridad alimentaria y puede afectar su salud mental.

- La crisis puede profundizar las desigualdades y la exclusión social y laboral que sufren los pueblos indígenas $y$ afrodescendientes: participan en gran medida en trabajos por cuenta propia no calificados y brechas salariales con respecto a los hombres no indígenas ni afrodescendientes, y la situación es particularmente grave en el caso de las mujeres. Los ingresos laborales por hora de las mujeres indígenas son menos de un tercio de los que reciben los hombres no indígenas ni afrodescendientes con el mismo nivel educativo. Asimismo, la discriminación estructural y el racismo dificultan el acceso efectivo de las personas indígenas y afrodescendientes a los servicios de salud.

- Las desigualdades en el acceso al agua, al saneamiento, a los sistemas de salud y a la vivienda (y el consecuente hacinamiento), así como la desigualdad en las propias condiciones de salud, pueden traducirse en mayores tasas de contagio y mortalidad por COVID-19 entre las poblaciones rurales, las poblaciones urbanas marginales, los pueblos indígenas y los afrodescendientes. Por ejemplo, al 9 de abril de 2020 los afrodescendientes representaban el $45,2 \%$ de las muertes por COVID-19 del Brasil, pese a representar solo el 37,4\% de las hospitalizaciones (Ministerio de la Salud, 2020).

- Las medidas de confinamiento pueden ampliar las barreras que encuentran las personas con discapacidad para acceder al sistema educativo y a un trabajo decente con ingresos suficientes y protección social; esta situación es especialmente grave para quienes, debido a su situación económica, no cuenten con los dispositivos requeridos para continuar con sus actividades educativas o laborales desde el hogar.

- Las personas migrantes se ven afectadas por el cierre de las fronteras, las dificultades de desplazamiento y el incremento del desempleo. Su acceso a los sistemas de salud y a la protección social es deficitario a causa de la escasa oferta para los migrantes, así como por su temor a ser identificados cuando dicha oferta está disponible. Estos problemas se agudizan en el caso de la niñez migrante - acompañada o no- en situación de desplazamiento interno y ante el posible aumento de la xenofobia y la discriminación y el racismo en contra de los migrantes (UNICEF, 2020).

- Las personas en situación de calle están sobrexpuestas al riesgo de enfermar por el COVID-19 producto de su carencia de vivienda, alimentación y acceso a la salud. También es el caso de las personas privadas de la libertad, debido al alto riesgo de contagio derivado de sus condiciones de reclusión. 


\section{Medidas emergentes y reforzamiento de las medidas existentes de protección social}

- El primer caso de COVID-19 en América Latina y el Caribe fue registrado en el Brasil el 26 de febrero de 2020. A partir del 13 de marzo, los Gobiernos de la región comenzaron a anunciar medidas de protección social como reacción ante la caída abrupta de los ingresos de los trabajadores y de los hogares, especialmente los más vulnerables (véase el cuadro 4).

Cuadro 4 | América Latina y el Caribe: medidas de protección social para hacer frente al COVID-19

\begin{tabular}{|c|c|c|c|c|}
\hline $\begin{array}{l}\text { Transferencias } \\
\text { monetarias }^{a}\end{array}$ & $\begin{array}{l}\text { Transferencias } \\
\text { en especie }\end{array}$ & $\begin{array}{l}\text { Suministro de } \\
\text { servicios básicos }\end{array}$ & $\begin{array}{l}\text { Protección social } \\
\text { para trabajadores } \\
\text { formales }\end{array}$ & $\begin{array}{l}\text { Otros apoyos } \\
\text { directos a personas } \\
\text { y familias }\end{array}$ \\
\hline $\begin{array}{l}\text { - Nuevos programas } \\
\text { de transferencias } \\
\text { monetarias } \\
\text { - Extensión de } \\
\text { las existentes } \\
\text { (anticipos } \\
\text { de entregas, } \\
\text { ampliación } \\
\text { de montos } \\
\text { y cobertura) }\end{array}$ & $\begin{array}{l}\text { - Alimentos } \\
\text { - Medicamentos } \\
\text { - Mascarillas } \\
\text { - Productos de aseo }\end{array}$ & $\begin{array}{l}\text { Suspensión o } \\
\text { exoneración del pago } \\
\text { de cuentas: } \\
\text { - Agua } \\
\text { - Electricidad } \\
\text { - Gas } \\
\text { - TIC (teléfono, } \\
\text { Internet, TV) }\end{array}$ & $\begin{array}{l}\text { - Reducción de } \\
\text { la exposición } \\
\text { al COVID-19 } \\
\text { (teletrabajo) } \\
\text { - Protección de } \\
\text { ingresos y puestos } \\
\text { de trabajo (seguros } \\
\text { de desempleo, } \\
\text { licencias, } \\
\text { prohibición } \\
\text { de despidos) }\end{array}$ & $\begin{array}{l}\text { - Alivios tributarios } \\
\text { - Facilidad de pago de } \\
\text { créditos e hipotecas } \\
\text { - Control de precios }\end{array}$ \\
\hline
\end{tabular}

Fuente: Comisión Económica para América Latina y el Caribe (CEPAL).

a Transferencias para personas y hogares en situación de pobreza y vulnerabilidad, incluyendo a los trabajadores informales.

\section{Protección social para la población en situación de pobreza y vulnerabilidad}

- La pandemia ha agudizado las dificultades de la población —especialmente la más pobre y vulnerable - para satisfacer sus necesidades básicas. Por ello, es preciso garantizar los ingresos, la seguridad alimentaria y los servicios básicos a un amplio grupo de personas cuya situación se ha vuelto extremadamente vulnerable y que no necesariamente estaban incluidas en los programas sociales existentes antes de la pandemia.

- Es clave contar con registros sociales amplios y actualizados para identificar a la población destinataria de este apoyo. Para evitar la propagación del virus, los programas sociales deben desincentivar las aglomeraciones de personas para la recolección de pagos y alimentos. En este sentido, los sistemas de pago electrónico son muy importantes.

- La focalización territorial es un instrumento efectivo para hacer llegar rápidamente a las poblaciones los beneficios y prestaciones que establezcan los Gobiernos.

- En la región, entre el 13 de marzo y el 24 de abril de 2020, 29 países adoptaron 126 medidas de protección social para ayudar a los hogares más pobres, vulnerables y precarizados a hacer frente a la pandemia. El número de países y de medidas aumentó casi diariamente durante la segunda mitad del mes de marzo (véanse el gráfico 3 y el cuadro A1 del anexo).

- Las principales medidas han sido la entrega de alimentos - elemento central del apoyo a la población en Guatemala y Honduras - y la creación de nuevas transferencias monetarias (un $33 \%$ y un $27 \%$ del total de las medidas adoptadas, respectivamente). A este tipo de medidas, le siguen en frecuencia la suspensión del pago de servicios básicos (agua, energía, teléfono e Internet) y el aumento del monto de las transferencias monetarias existentes (un 19\% y un 13\%, respectivamente). Finalmente, el anticipo de la entrega de los programas de transferencias existentes representa el $5 \%$ del total de las medidas, y el aumento de la cobertura poblacional de las transferencias monetarias existentes, el 4\% (véase el gráfico 4). 
Gráfico 3 | América Latina y el Caribe (29 países ${ }^{a}$ ): medidas de protección social para la población en situación de pobreza y vulnerabilidad anunciadas para enfrentar la pandemia, 13 de marzo a 24 de abril de 2020

(En número de medidas)

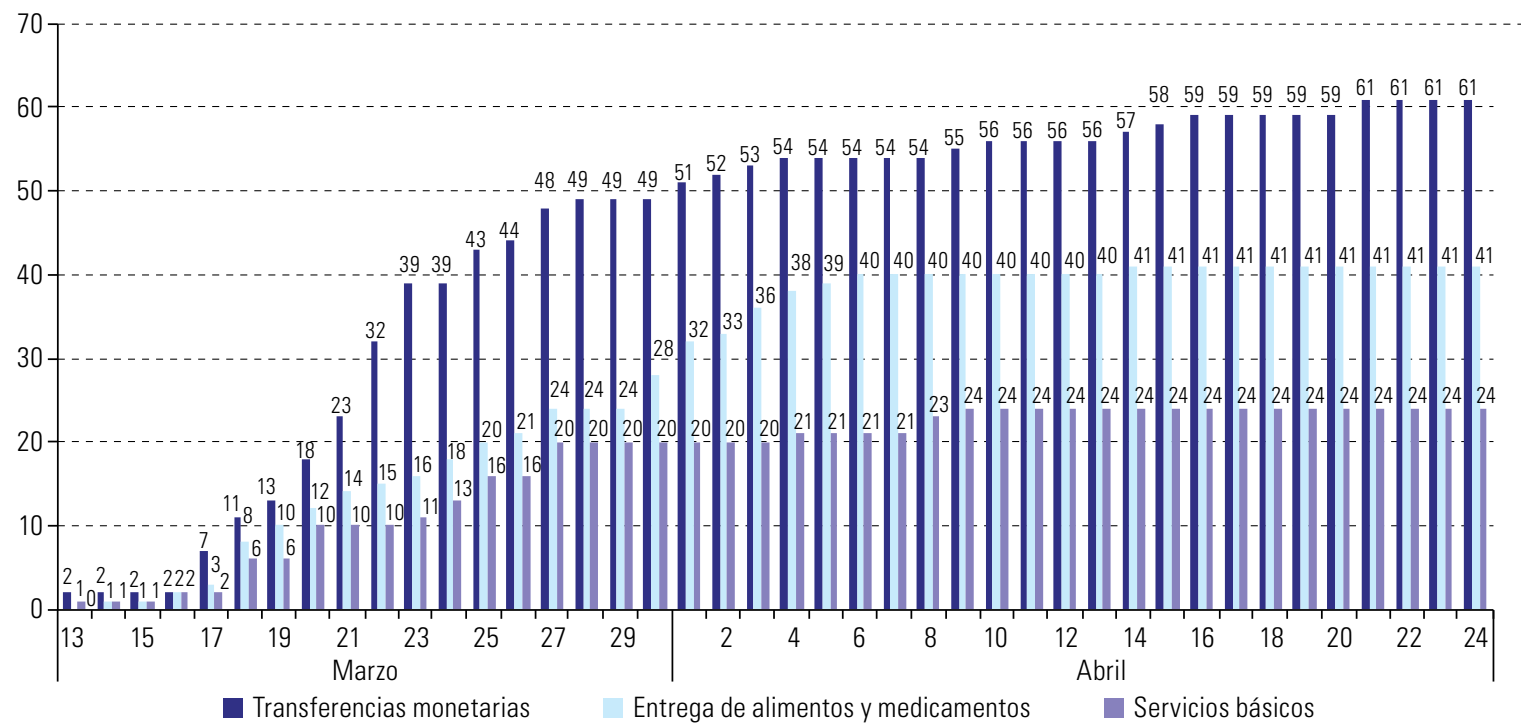

Fuente: Comisión Económica para América Latina y el Caribe (CEPAL).

a Los países considerados son: Antigua y Barbuda, Argentina, Bahamas, Barbados, Belice, Bolivia (Estado Plurinacional de), Brasil, Chile, Colombia, Costa Rica, Cuba, Ecuador, El Salvador, Granada, Guatemala, Guyana, Haití, Honduras, Jamaica, México, Panamá, Paraguay, Perú, República Dominicana, San Vicente y las Granadinas, Santa Lucía, Trinidad y Tabago, Uruguay y Venezuela (República Bolivariana de).

Gráfico 4 | América Latina y el Caribe (29 paísesª): medidas de protección social para la población en situación de pobreza y vulnerabilidad anunciadas para enfrentar los efectos de la pandemia del COVID-19, por tipo de medida, al 24 de abril de 2020

(En número de medidas y distribución porcentual)

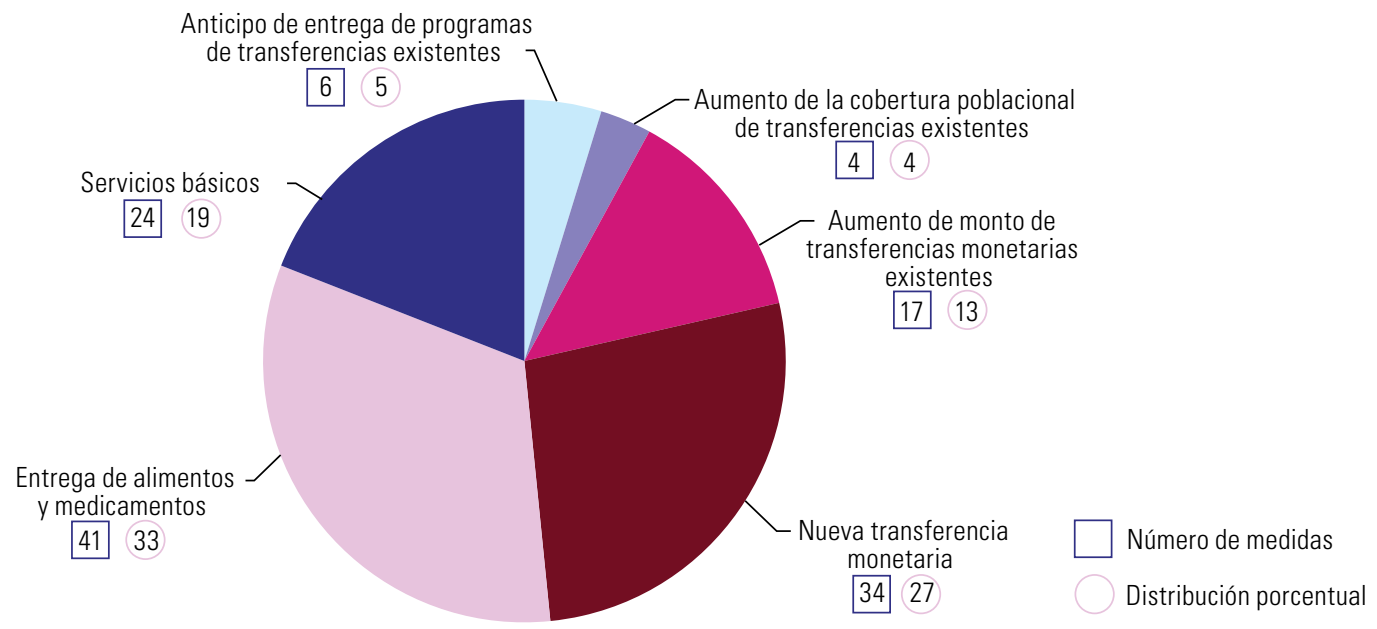

Fuente: Comisión Económica para América Latina y el Caribe (CEPAL).

a Los países considerados son: Antigua y Barbuda, Argentina, Bahamas, Barbados, Belice, Bolivia (Estado Plurinacional de), Brasil, Chile, Colombia, Costa Rica, Cuba, Ecuador, El Salvador, Granada, Guatemala, Guyana, Haití, Honduras, Jamaica, México, Panamá, Paraguay, Perú, República Dominicana, San Vicente y las Granadinas, Santa Lucía, Trinidad y Tabago, Uruguay y Venezuela (República Bolivariana de).

- Varios de los programas de transferencias monetarias existentes han suspendido las condicionalidades debido a que las familias se han visto imposibilitadas, por ejemplo, de enviar a sus hijos e hijas a la escuela.

- Las transferencias monetarias anunciadas para enfrentar los efectos de la pandemia del COVID-19 en los hogares pobres y vulnerables se presentan en cuatro modalidades, no excluyentes entre sí:

i) Nuevas transferencias monetarias. La modalidad más frecuente en la región (23 países). Por ejemplo, el Estado Plurinacional de Bolivia anunció la creación del Bono Familia, que entregará 500 bolivianos (70 dólares) una única vez a las familias de escasos recursos con 
hijos que asistan al nivel escolar primario y que no puedan acceder al desayuno escolar durante el tiempo que dure la cuarentena. La Argentina ha implementado el Ingreso Familiar de Emergencia, una transferencia de 10.000 pesos argentinos (154 dólares) por un mes (recientemente se anunció la extensión por un mes más), que tendrá una cobertura de 3,6 millones de hogares. A su vez, el Brasil ha aprobado un bono de emergencia para trabajadores independientes o informales cuyos ingresos per cápita mensuales sean inferiores a la mitad de un salario mínimo y cuyo ingreso familiar no supere tres salarios mínimos. El bono es de 600 reales mensuales por persona (117 dólares), con un máximo de 1.200 reales por familia, durante tres meses; los hogares monoparentales cuya jefa de hogar sea mujer recibirán 1.200 reales. En el ámbito subnacional, Ciudad de México ha establecido una nueva transferencia con una vigencia inicial de 45 días.

ii) Aumento del monto de las transferencias monetarias existentes. Medida adoptada por 11 países. La Argentina ha aumentado los montos a todos los receptores de programas como la Asignación Universal por Hijo y la Asignación por Embarazo para Protección Social, así como de las pensiones no contributivas. Las prestaciones adicionales van desde los 44 a los 150 dólares, y el monto más alto corresponde a las pensiones por discapacidad. Colombia anunció un giro adicional para los usuarios de los programas Jóvenes en Acción, Familias en Acción y Colombia Mayor, y el Paraguay, un pago adicional en abril del programa de transferencias condicionadas Tekoporã. El Uruguay, por su parte, anunció que el monto entregado mediante la Tarjeta Uruguay Social y las Asignaciones Familiares-Plan de Equidad se duplicaría una única vez. Por último, Ciudad de México ha incrementado el monto de la transferencia destinada a todos los estudiantes del sistema público básico (Mi Beca para Empezar).

iii) Anticipo de la entrega de transferencias existentes. Hasta el 24 de abril de 2020, el Brasil, Colombia, México y el Paraguay habían anunciado pagos anticipados de las transferencias monetarias dirigidas primordialmente a personas mayores y personas con discapacidad. El Paraguay, por ejemplo, anunció el anticipo del pago de la Pensión Alimentaria para las Personas Adultas Mayores en Situación de Pobreza. México ha adelantado los pagos equivalentes a cuatro meses de pensiones a 8 millones de personas mayores y 1 millón de personas con discapacidad.

iv) Aumento de la cobertura poblacional de las transferencias existentes. Cuatro países han anunciado el aumento de la cantidad de perceptores de los programas existentes. La Argentina anunció la entrega de más de 1,5 millones de tarjetas adicionales para las transferencias del programa Tarjeta Alimentaria, destinado a la adquisición de los bienes de la canasta básica alimentaria. El Brasil anunció un aumento de 1,2 millones de usuarios del programa Bolsa Família. México ampliará la cobertura del programa Sembrando Vida a 200.000 agricultores, y Trinidad y Tabago anunció el aumento de la cobertura de la tarjeta de alimentos para ayudar a las familias que tengan niños con derecho a alimentación escolar que no cuenten con una tarjeta de alimentos y a las familias con integrantes que hayan sido despedidos o hayan visto reducidos sus ingresos durante este período.

- Al 11 de abril, 14 países habían implementado transferencias monetarias para mitigar la caída de los ingresos de los trabajadores informales, así como de otros trabajadores vulnerables como los que operan por cuenta propia. Este mecanismo es una innovación en la protección social de la región. Las medidas consisten en un pago único o periódico (por un máximo de tres meses) y el monto transferido a cada persona u hogar varía considerablemente (véase el gráfico 5). En Costa Rica, por ejemplo, el Bono Proteger implica una transferencia individual mensual de 125.000 colones costarricenses (220 dólares) durante tres meses a trabajadores informales y trabajadores independientes, así como a personas despedidas, cuyo contrato laboral haya sido suspendido o cuya jornada laboral se haya visto reducida más de un $50 \%$. Quienes hayan experimentado una disminución de su jornada laboral de un 50\% o menos recibirán 62.500 colones costarricenses por mes (110 dólares).

- La CEPAL estima que, hasta el 24 de abril de 2020, las transferencias monetarias implementadas en 22 países para apoyar a las familias en situación de pobreza y vulnerabilidad durante la crisis llegarían a 90,5 millones de hogares (385,7 millones de personas, el 58\% de la población). El gasto previsto durante tres meses correspondería a 36.830 millones de dólares, alrededor de un $0,7 \%$ del PIB de 2020. Los países con la mayor cobertura absoluta de hogares son el Brasil (38,2 millones), Colombia (11,3 millones), la Argentina (8,4 millones) y el Perú (4,8 millones). Esta cifra representa cerca del doble de los costos anuales de los programas de transferencias condicionadas antes de la crisis, que se situaban en torno al 0,35\% del PIB. 
Gráfico 5 | América Latina y el Caribe (13 países): monto de las transferencias dirigidas a trabajadores informales, según tipo de receptor (persona o familia) y duración, al 11 de abril de 2020a

(En dólares)

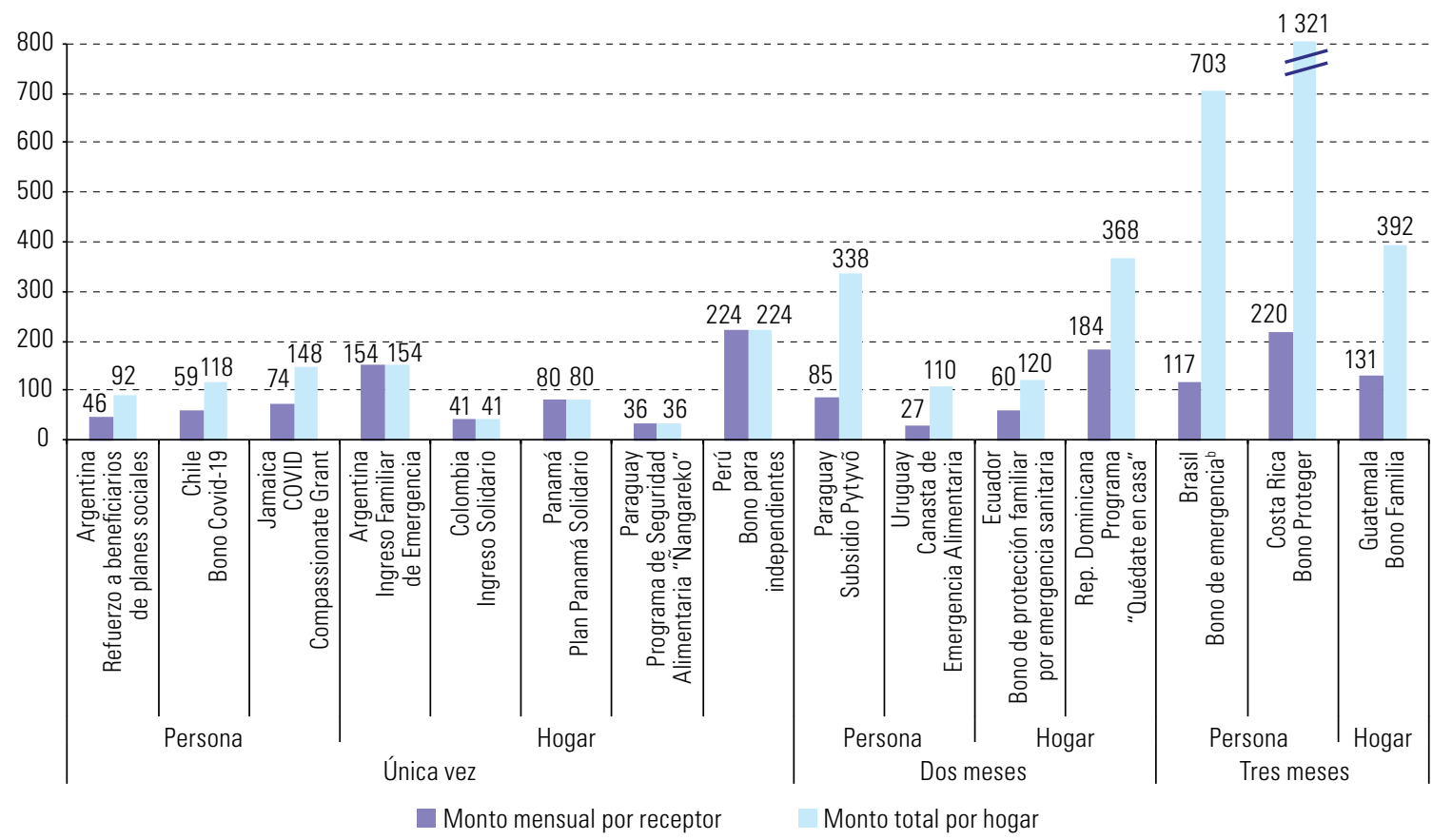

Fuente: Comisión Económica para América Latina y el Caribe (CEPAL).

a En el caso de las medidas en las que el receptor es la persona (o la "carga familiar", es decir, una persona dependiente, como niños, niñas y adolescentes), se supone la recepción de dos montos por familia para hacer el cálculo del monto total por familia. La República Bolivariana de Venezuela ha implementado el Bono Disciplina y Solidaridad para los trabajadores de la economía informal; sin embargo, no se cuenta con información sobre los montos de las transferencias.

b Incluye también a personas con contrato laboral suspendido, jornada laboral reducida o trabajadores independientes cuyos ingresos fueron afectados como consecuencia del COVID-19.

- La entrega de alimentos es una medida que ha sido adoptada por 24 países hasta la fecha, ya sea mediante la entrega directa a los hogares, o a través de las escuelas o los comedores comunitarios. En varios países, la distribución de alimentos se ha basado en los programas de alimentación escolar existentes, a los que se ha dado continuidad a pesar del cierre de las escuelas, adaptándolos mediante un calendario de distribuciones periódicas y el incremento de la cantidad de raciones para evitar aglomeraciones.

- Entre los países que están entregando alimentos, se encuentran Costa Rica, donde mediante la estrategia Alimentos en Casa se entregan alimentos y medicamentos a domicilio a niños, niñas y madres gestantes y en período de lactancia; la República Dominicana, que, a través del Plan de Asistencia Social de la Presidencia (PASP), los Comedores Económicos del Estado Dominicano (CEED), el Instituto Nacional de Atención Integral a la Primera Infancia (INAIPI) y las Estancias Infantiles, entrega en las escuelas canastas de alimentos y kits de prevención a las familias vulnerables, y la República Bolivariana de Venezuela, que entrega cajas de alimentos a los estudiantes de establecimientos educativos oficiales y a las familias más vulnerables. Asimismo, el Uruguay está entregando una canasta de emergencia alimentaria a los trabajadores informales que no reciban otras prestaciones del Estado.

- En 17 países se han adoptado medidas para asegurar y facilitar el suministro de servicios básicos a los hogares más vulnerables durante el período de aislamiento social. Por ejemplo, Guatemala, Honduras y Panamá anunciaron medidas que aseguran el suministro de energía eléctrica a los hogares a través de la reconexión de servicios, subsidios y facilidades de pago. La Argentina, Chile, el Ecuador y El Salvador, entre otros, han tomado medidas para evitar el corte por no pago de todos los servicios básicos de los hogares, incluyendo agua, teléfono e Internet.

- Algunas medidas cuentan con la colaboración y participación del sector privado y la sociedad civil. En Colombia, se generó una red virtual de aportes solidarios para la compra de productos y alimentos básicos para la población en situación de vulnerabilidad sin acceso a los actuales 
beneficios de los sistemas de seguridad social. En el Ecuador, se creó una plataforma para comprar canastas de alimentos que serán entregadas a nivel nacional por las Fuerzas Armadas a las familias en situación de vulnerabilidad. En las Islas Caimán, el Departamento de Educación trabaja con una organización no gubernamental para la entrega de cupones para alimentos que pueden canjearse en los supermercados.

\section{Protección social para trabajadores formales}

- En la mayoría de los países, los servicios no esenciales han sido paralizados para asegurar el distanciamiento social. Aunque los trabajadores formales que trabajan en sectores esenciales aún reciben sus ingresos, muchos trabajadores formales ya no reciben ingresos o los reciben de manera parcial. Esta situación incluye a asalariados y a dueños de micro, pequeñas y medianas empresas.

Algunos países han adoptado medidas de apoyo económico a los trabajadores de la salud, quienes corren un gran riesgo de contagio. Por ejemplo, la Argentina ha implementado un bono extraordinario para el personal sanitario de 5.000 pesos argentinos (76 dólares) mensuales durante cuatro meses (de abril a julio).

- Las medidas de protección social para los trabajadores formales son de dos tipos. El primer tipo de medidas está destinado a reducir la exposición al virus de los trabajadores y garantizar la continuidad de la actividad económica, y el segundo, a asegurar los ingresos o los puestos de trabajo (véase el gráfico 6). Además, existen medidas indirectas de protección del empleo formal, que no se analizan en este informe, como las de apoyo a las empresas mediante, por ejemplo, la reprogramación del pago de deudas e impuestos o los préstamos especiales.

Gráfico 6 | América Latina y el Caribe (25 países ${ }^{a}$ ): países que han adoptado medidas de protección social para los trabajadores formales, al 11 de abril de 2020

(En número de países)

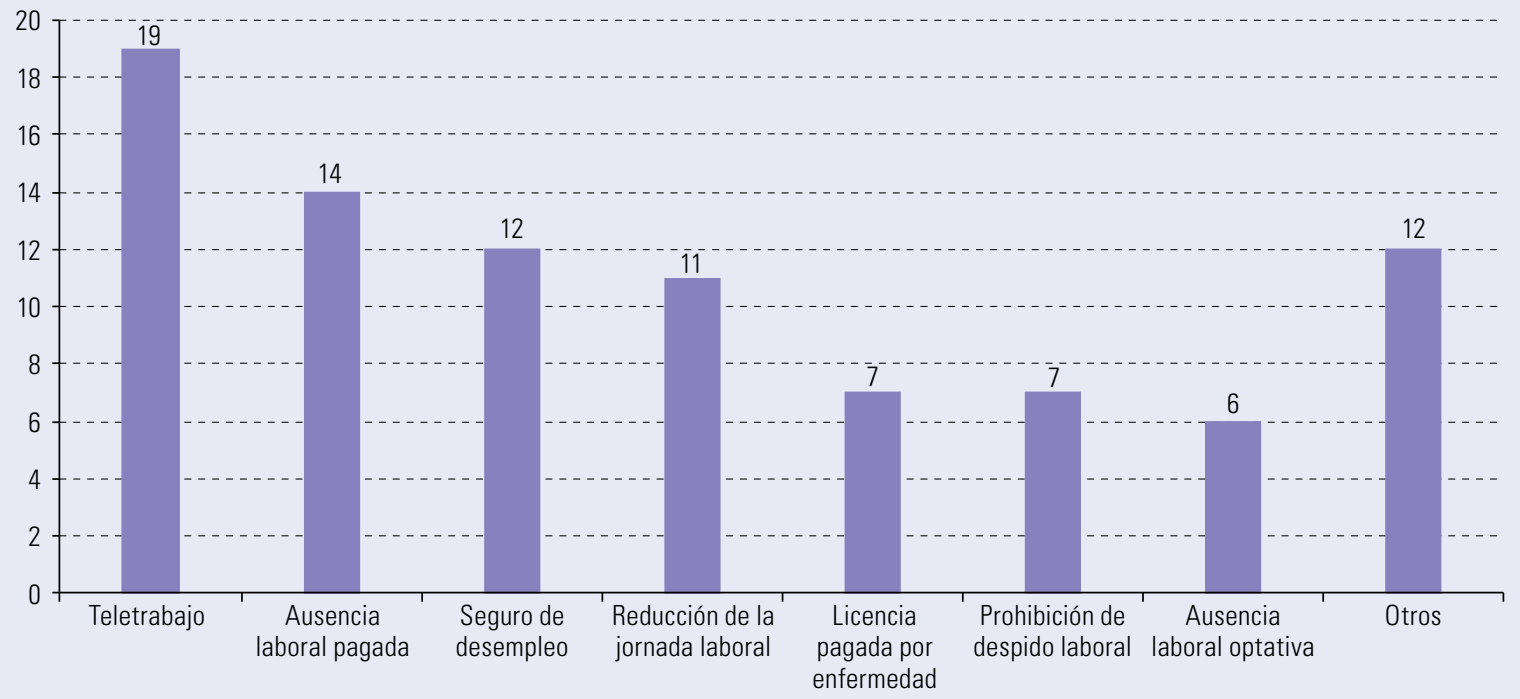

Fuente: Comisión Económica para América Latina y el Caribe (CEPAL).

a Los países considerados son: Argentina, Bahamas, Barbados, Belice, Bolivia (Estado Plurinacional de), Brasil, Chile, Colombia, Costa Rica, Cuba, Ecuador, El Salvador, Granada, Guatemala, Guyana, Haití, Jamaica, México, Panamá, Paraguay, Perú, Rep. Dominicana, Trinidad y Tabago, Uruguay y Venezuela (República Bolivariana de).

- Se han implementado medidas de distanciamiento físico mediante teletrabajo en el sector público y en el privado. Por ejemplo, en Chile, los funcionarios públicos que forman parte de un grupo de riesgo pueden trabajar desde su hogar. En la Argentina, el teletrabajo se implementa en el caso de todos los trabajadores públicos y privados que puedan trabajar desde su casa, en un contexto de aislamiento social, preventivo y obligatorio. Otras medidas promueven la seguridad y la higiene en el lugar de trabajo, mediante la obligación de usar mascarillas o de mantener la distancia entre los empleados.

- En 11 países, se han implementado medidas de reducción de la jornada laboral, que contribuyen a disminuir la exposición en el lugar de trabajo y a preservar el empleo en las empresas afectadas. Algunos ejemplos son la limitación del horario de atención de los comercios 
no esenciales en Jamaica, la limitación de los horarios bancarios en Guyana o la reducción del horario de trabajo en el sector público en el Paraguay. Costa Rica aprobó una ley que autoriza la reducción temporal de las jornadas de trabajo, que permitiría proteger los puestos de los trabajadores en virtud de la declaración de emergencia nacional.

- La protección de los ingresos de las trabajadoras y los trabajadores formales incluye políticas muy diversas, como el aseguramiento de los ingresos ante las ausencias laborales, las licencias pagadas por enfermedad, la activación de medidas relacionadas con el seguro de desempleo, las prohibiciones de despido y las ausencias laborales optativas.

- El pago del salario durante el período de ausencia laboral es una medida que se dirige sobre todo a los trabajadores más vulnerables a la pandemia, como las personas mayores, las personas con problemas de salud preexistentes y las mujeres embarazadas. En algunos casos, también se incluye a los trabajadores formales que no pueden asistir a su trabajo por la emergencia sanitaria. En México, se ha decidido mantener el pago completo de los salarios en el caso de todos los trabajadores de actividades no esenciales. En la República Dominicana, las empresas pagarán el salario de una semana a los trabajadores del sector privado a los que todavía no les correspondan vacaciones. En el Perú, cuando la naturaleza del trabajo no sea compatible con el trabajo a distancia, las empresas deben garantizar a sus empleados el salario durante su ausencia. En Trinidad y Tabago, los trabajadores pueden quedarse en casa con sus hijos sin ser penalizados monetariamente.

- Los seguros de desempleo y las licencias por enfermedad también se han utilizado para garantizar un ingreso a los trabajadores formales desvinculados. En la Argentina, por ejemplo, el seguro de desempleo brindará a los trabajadores asalariados registrados legalmente y despedidos sin justa causa un pago mensual, asignaciones familiares y cobertura médica, cuya duración varía según el tiempo durante el cual efectivamente se haya trabajado y contribuido al sistema de seguridad social (Fondo Nacional de Empleo). En otros casos, se ha creado un fondo para otorgar un seguro de desempleo sectorial a los trabajadores de los sectores económicos particularmente afectados, como en el sector del turismo en los países del Caribe. En el Brasil, se aprobó un pago de 15 días de licencia por enfermedad para los contagiados.

- También se han implementado diferentes medidas de prohibición de despido para proteger el empleo y los ingresos laborales. Estas medidas son de índole muy diversa y están relacionadas con la existencia de una declaración de estado de emergencia, restricciones sanitarias que impidan llegar al lugar de trabajo, la prohibición de usar el COVID-19 como causal de despido o la prohibición de efectuar despidos durante un período determinado. Por ejemplo, en la Argentina, el Gobierno nacional prohibió los despidos sin justa causa y por las causales de falta o disminución de trabajo y fuerza mayor durante un plazo de 60 días. Asimismo, en El Salvador no podrá ser despedido ningún trabajador o trabajadora que se encuentre en cuarentena.

- Las ausencias laborales optativas están vinculadas en muchos casos al uso anticipado de vacaciones, como en el Brasil y el Paraguay, y a rotaciones laborales o compensatorias. En el primer caso, la rotación compensatoria se basa en un "banco de horas", en el que los empleados acumulan horas laborales a su favor o las deben a su empleador. Este acuerdo debe ser negociado formalmente de manera individual o colectiva entre los trabajadores y el empleador.

- Entre otras medidas, destacan los subsidios a la planilla de salarios de empresas y sectores económicos vulnerables y los créditos destinados a que las empresas no despidan a sus trabajadores. En la Argentina, el Programa de Recuperación Productiva (REPRO) entrega una suma fija mensual de hasta un monto equivalente al salario mínimo durante un plazo de hasta 12 meses, destinada a completar el sueldo de la categoría laboral de las y los trabajadores de empresas cuyos ingresos por ventas disminuyan a causa de la emergencia. El Perú ha aprobado un decreto de urgencia que faculta pagar a cada empleador un subsidio no superior al $35 \%$ de la suma correspondiente a las remuneraciones brutas mensuales de sus trabajadores que ganen hasta 1.500 soles (436 dólares). En Chile, los trabajadores que ganaban el salario mínimo (301.000 pesos chilenos) en febrero de 2020, recibirán una suma adicional de 59.200 pesos (70 dólares) y esta medida se extiende de manera decreciente a quienes ganan hasta 384.363 pesos. Se estima que este ingreso mínimo garantizado, que se estaba gestionando antes de la emergencia sanitaria como parte de las respuestas al estallido social, beneficiará a 670.000 trabajadores. 
- En el ámbito de las pensiones, se han aplicado cuatro tipos de medidas: i) entrega de bonos extraordinarios para los jubilados que cobran las pensiones más bajas del sistema previsional, a veces complementados con bonos de montos menores para quienes cuentan con pensiones más elevadas (en la Argentina, por ejemplo, se entrega un bono extraordinario de 3.000 pesos argentinos (45 dólares) a los perceptores de jubilaciones muy bajas); ii) anticipo de los pagos de las pensiones durante un número definido de meses, como en las Bahamas, Belice y el Brasil; iii) retiro de fondos de las cuentas de capitalización individual por parte de los trabajadores independientes (en el Perú, los trabajadores independientes que no hayan aportado a su fondo de pensiones en los últimos 12 meses pueden retirar fondos de su cuenta por un máximo de hasta 2.000 soles, o 590 dólares), y iv) suspensión del pago de las contribuciones por parte de los empleadores (en la Argentina, por ejemplo, se dispuso la postergación o reducción de hasta el 95\% del pago de contribuciones patronales para las empresas con dificultades financieras). Además, es necesario considerar los efectos sobre los sistemas de pensiones en su conjunto (véase el recuadro 1).

Recuadro 1 | Efectos de la crisis en los sistemas de pensiones

Los sistemas de pensiones se verán afectados por la pandemia. La afiliación o cotización a los sistemas disminuirá, especialmente en los países más expuestos al incremento del desempleo y la informalidad. Ello tendrá efectos en los ingresos por cotizaciones y en la densidad de cotizaciones en el momento del retiro, y podría conllevar la reducción de las prestaciones y una profundización de las actuales desigualdades de género.

Es esperable que los sistemas de reparto con reservas basados en el modelo de capitalización parcial colectiva deban hacer frente a efectos financieros vinculados con la disminución de los ingresos por cotizaciones y la caída de la rentabilidad de los fondos de reserva.

En los sistemas que se rigen por una lógica de capitalización individual como componente principal o que contemplan un componente complementario en modelos paralelos o mixtos, puede esperarse una fuerte reducción de los fondos acumulados y el nivel de las prestaciones de quienes estén por pensionarse. Esta situación puede afectar especialmente a Bolivia(Estado Plurinacional de), Chile, EI Salvador, México y la República Dominicana, países que cuentan con un modelo de capitalización individual (modelo sustitutivo), y también a Colombia, el Perú, Costa Rica, Panamá y el Uruguay, que cuentan con sistemas paralelos o mixtos.

En los sistemas de capitalización individual, la rentabilidad bruta en el momento del retiro puede verse afectada por pérdidas nominales y variaciones en el valor de los fondos. Si bien los efectos deben analizarse a largo plazo, y la existencia de multifondos puede mitigar este problema, ello no elimina completamente el riesgo, que afecta más intensamente a quienes están por pensionarse o deben pensionarse obligatoriamente por razones de salud o discapacidad.

Es importante resguardar la sostenibilidad financiera de los sistemas de pensiones y, especialmente, el derecho de las personas a acceder a una prestación adecuada al retirarse. Tras la emergencia, se abrirá un espacio para profundizar la discusión sobre la reforma de los sistemas de pensiones ya iniciada en varios países de la región, considerando que los esfuerzos centrados solo en la capacidad de ahorro individual no responden a las demandas del ámbito de la protección social y la importancia de avanzar en mecanismos solidarios.

Fuente: Comisión Económica para América Latina y el Caribe (CEPAL).

\section{Otros apoyos directos a las personas y las familias}

- Los países han adoptado otras medidas que atenúan y reducen el gasto de las personas y las familias. Al 24 de abril de 2020, 22 países han anunciado $\mathbf{4 5}$ medidas adicionales, de las cuales el $60 \%$ son facilidades de pago de créditos e hipotecas, el $22 \%$ son alivios tributarios y el $18 \%$ corresponden a controles de precios (véase el gráfico 7).

- Hasta la fecha, 20 países han ofrecido facilidades de pago de créditos a los hogares, entre las que se incluyen el aplazamiento del pago de cuotas, la readecuación y el refinanciamiento de préstamos, la exención de pagos o la suspensión de intereses de mora y multas durante el tiempo que dure la emergencia. En tres países, fue el sector bancario el que anunció las medidas, mientras que, en los restantes, fueron iniciativas públicas impuestas a los bancos privados o el resultado de acuerdos entre los gobiernos y la banca. 
Gráfico 7 | América Latina y el Caribe (22 países ${ }^{a}$ ): otras medidas de apoyo directo a las personas y las familias anunciadas para enfrentar los efectos de la pandemia del COVID-19, por tipo de medida, al 24 de abril de 2020 (En número de medidas y distribución porcentual)

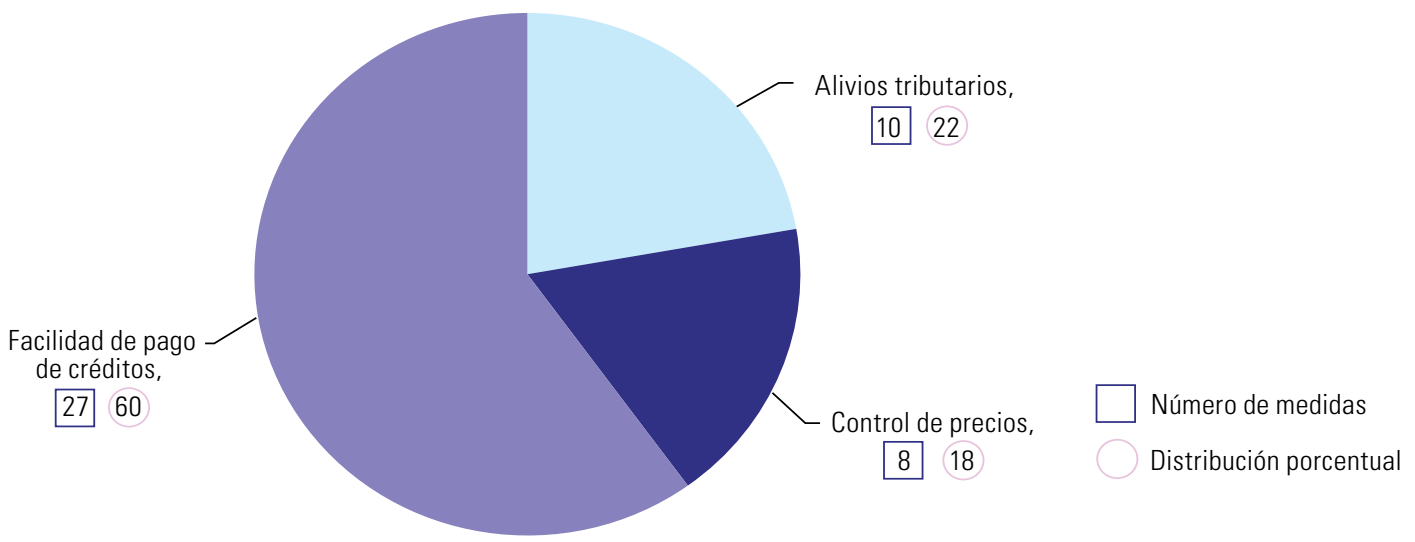

Fuente: Comisión Económica para América Latina y el Caribe (CEPAL).

a Los países considerados son: Argentina, Barbados, Bolivia (Estado Plurinacional de), Chile, Colombia, Costa Rica, Cuba, Dominica, Ecuador, El Salvador, Granada, Guatemala, Guyana, Honduras, Jamaica, México, Panamá, Paraguay, República Dominicana, Trinidad y Tabago, Uruguay y Venezuela (República Bolivariana de).

- Siete países han otorgado alivios tributarios a las familias más afectadas, que consisten principalmente en la exoneración de multas en el pago de impuestos, la suspensión de fechas de cobranza y de remates por falta de pago, y facilidades para el pago de impuestos en los meses posteriores al término del período de la cuarentena. Por otra parte, seis países han establecido precios máximos para un conjunto de alimentos y medicamentos, a fin de que el aumento de precios no afecte todavía más a las familias más pobres y de garantizar el adecuado abastecimiento.

\section{Un ingreso básico para satisfacer necesidades y sostener el consumo}

- Para enfrentar los impactos socioeconómicos de la crisis, la CEPAL propone que los gobiernos garanticen transferencias monetarias temporales para satisfacer necesidades básicas y sostener el consumo de los hogares, lo que será crucial para lograr una reactivación sólida y relativamente rápida.

- Desde una perspectiva de largo plazo, la CEPAL reitera que el alcance de esas transferencias debe ser permanente, ir más allá de las personas en situación de pobreza y llegar a amplios estratos de la población muy vulnerables a caer en ella, como los estratos de ingresos bajos no pobres y los medios bajos. Esto permitiría avanzar hacia un ingreso básico universal que se debe implementar gradualmente en un período definido de acuerdo con la situación de cada país (véase el recuadro 2). Esta consideración es importante pues la superación de la pandemia tomará su tiempo y las sociedades deberán coexistir con el coronavirus, lo que dificultará la reactivación económica y productiva.

- En la coyuntura de la crisis del COVID es necesario considerar alternativas acotadas y de menor alcance temporal, pero que señalen el camino para las acciones a implementar una vez superada la pandemia.

- Para estimar el costo de estas transferencias monetarias en una perspectiva de corto plazo, se considera que su duración mínima debería ser de tres meses, aunque seis meses o un año darían una mejor protección a la población. Las transferencias serían para cada persona y por un equivalente a una línea de pobreza extrema (LPE), que representa el costo per cápita de adquirir una canasta básica de alimentos, o a una línea de pobreza (LP), que permite cubrir también otras necesidades básicas. La estimación no considera los costos de gestionar las transferencias que, según la Organización Internacional del Trabajo (OIT), serían del orden del 5\% del monto de las transferencias (Durán-Valverde y otros, 2019). 
Recuadro 2 | Una propuesta de ingreso básico universal en México

El debate sobre un ingreso ciudadano universal ha adquirido una mayor presencia ante la crisis sanitaria. Para su puesta en marcha es preciso determinar un monto por persona congruente con el objetivo de erradicar la pobreza y mejorar la distribución del ingreso.

En el caso de México, se han considerado dos opciones: otorgar un salario mínimo general o dar un monto equivalente a la línea de bienestar urbana o a la línea de bienestar mínimo urbana, que estima el Consejo Nacional de Evaluación de la Política de Desarrollo Social (CONEVAL). Si se otorgara una línea de bienestar mínima, equivalente al costo de la canasta alimentaria de las zonas urbanas (unos 73 dólares mensuales en marzo de 2020), sería necesario un desembolso equivalente al 10,3\% del PIB estimado para 2020. Un programa más cercano a los objetivos del ingreso básico universal y que otorgara un salario mínimo (unos 167 dólares mensuales) o un monto equivalente a la canasta alimentaria y no alimentaria (unos 144 dólares mensuales), elevaría el monto requerido al 23,5\% del PIB en el primer caso y al 20,2\% del PIB en el segundo. Considerando estos montos, la implementación de un ingreso ciudadano universal se realizaría como un proceso de avance gradual de largo plazo.

Fuente: Comisión Económica para América Latina y el Caribe (CEPAL).

- En cuanto a la población objetivo, se calcula el costo de transferencias para cinco grupos: i) todas las personas (universal); ii) toda la población en situación de pobreza; iii) todos los trabajadores informales de 18 a 64 años; iv) todos los niños, niñas y adolescentes de 0 a 17 años, y v) todas las personas mayores de 65 años. Las combinaciones de población objetivo, monto de las transferencias y duración deberán tomar en cuenta la realidad de cada país.

- Como promedio (ponderado) para los países de la región, el costo de las transferencias monetarias varía entre un mínimo del $\mathbf{0 , 2} \%$ del PIB por una transferencia equivalente a una línea de extrema pobreza (67 dólares de 2010) durante tres meses para todas las personas mayores de 65 años y un máximo del $\mathbf{9 , 8} \%$ del PIB por una transferencia equivalente a una línea de pobreza (143 dólares) durante seis meses para todas las personas (transferencia universal) (véase el gráfico 8).

- Más allá del financiamiento, existen problemas operacionales para implementar estas transferencias. Desde el punto de vista sanitario, lo ideal es promover el distanciamiento social y hacer transferencias por medios electrónicos. Sin embargo, dado que una parte importante de la población no está bancarizada, hay que encontrar otras soluciones, como pagos por teléfono celular o distribución de efectivo, pero evitando aglomeraciones. Asimismo, para implementar transferencias en el muy corto plazo, es necesario contar con amplios registros sociales actualizados y considerar los vínculos con el sistema de protección social y los mecanismos existentes, como seguros de desempleo, pensiones, asignaciones familiares y transferencias condicionadas.

- Al considerar el gasto regional en programas de protección social no contributivos como los programas de transferencias condicionadas y las pensiones sociales, es posible estimar el costo adicional de implementación de esas transferencias. La estimación resulta de considerar del costo total el gasto en ambos programas para las transferencias universales y a todas las personas en situación de pobreza, el gasto en programas de transferencias condicionadas para la población de niños, niñas y adolescentes y en pensiones sociales para los adultos mayores. Dado que antes de la actual crisis no había transferencias específicas para los trabajadores informales, los costos de las transferencias para este grupo de la población se consideran en su totalidad como adicionales.

- Una transferencia por un monto equivalente a una línea de pobreza durante seis meses demandaría un gasto adicional del $\mathbf{2 , 8} \%$ del PIB para abarcar a todas las personas que se encontrarán en situación de pobreza en 2020. Si además se considera que hasta la fecha los países están gastando el $0,7 \%$ del PIB regional en transferencias monetarias y de alimentos para hacer frente a la emergencia, el gasto adicional es del 2,1\% del PIB. En los otros casos, el esfuerzo fiscal es del $\mathbf{2 , 7} \%$ del PIB para una transferencia a todos los niños, niñas y adolescentes, el 0,6\% del PIB para las personas mayores de 65 años y el $9,2 \%$ del PIB para una transferencia a todas las personas, es decir universal (véase el gráfico 9). 
Gráfico $8 \mid$ América Latina (18 países ${ }^{a}$ ): estimación del costo de transferencias monetarias equivalentes a una línea de pobreza y una línea de extrema pobreza para enfrentar el impacto de la pandemia del COVID-19, según población objetivo, duración y cobertura de la población totab ${ }^{\mathrm{c}}$

(En porcentajes del PIB y de la población total)

A. Línea de pobreza

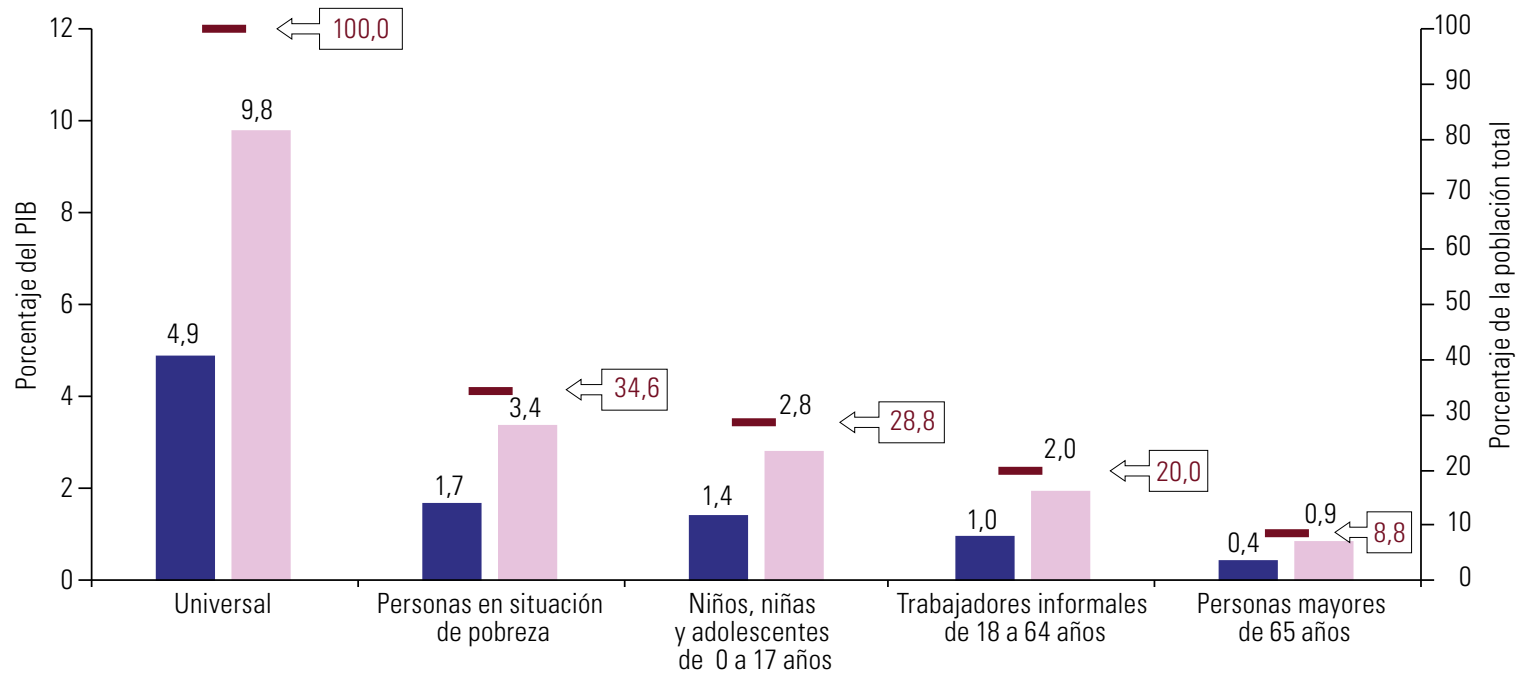

B. Línea de extrema pobreza

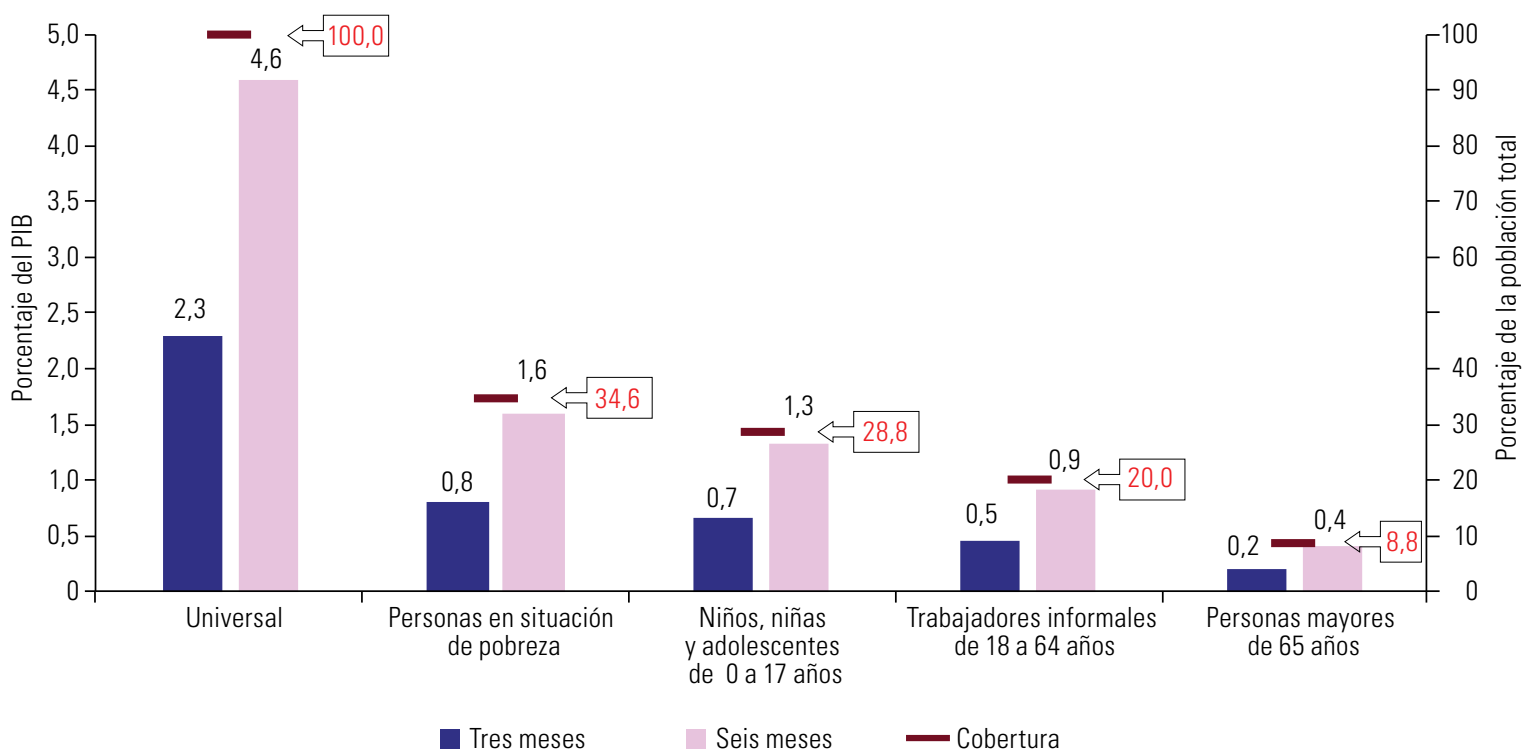

Fuente: Comisión Económica para América Latina y el Caribe (CEPAL).

a Los países considerados son: Argentina, Bolivia (Estado Plurinacional de), Brasil, Chile, Colombia, Costa Rica, Ecuador, El Salvador, Guatemala, Honduras, México, Nicaragua, Panamá, Paraguay, Perú, República Dominicana, Uruguay y Venezuela (República Bolivariana de).

b Estimación basada en una caída del 5,3\% del PIB en 2020 y considerando una población pobre de 214,7 millones en el mismo año. No se toman en cuenta los costos administrativos necesarios para efectuar las transferencias.

c La categoría trabajadores informales corresponde a trabajadores en sectores de baja productividad, lo que incluye: servicio doméstico, trabajadores por cuenta propia no calificados, trabajadores no calificados en microempresas y microempresarios.

- Teniendo en cuenta el limitado espacio fiscal de los países de la región, la alternativa más viable en la situación actual sería la de transferencias de un monto igual a una línea de pobreza durante seis meses. Esta consideración deberá ser ajustada o expandida según las diferentes situaciones nacionales. 


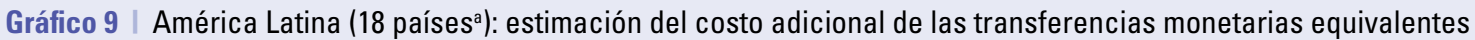
a una línea de pobreza para enfrentar el impacto de la pandemia del COVID-19, según población objetivo y duración ${ }^{b}$ (En porcentajes del PIB)

\section{A. Universal}

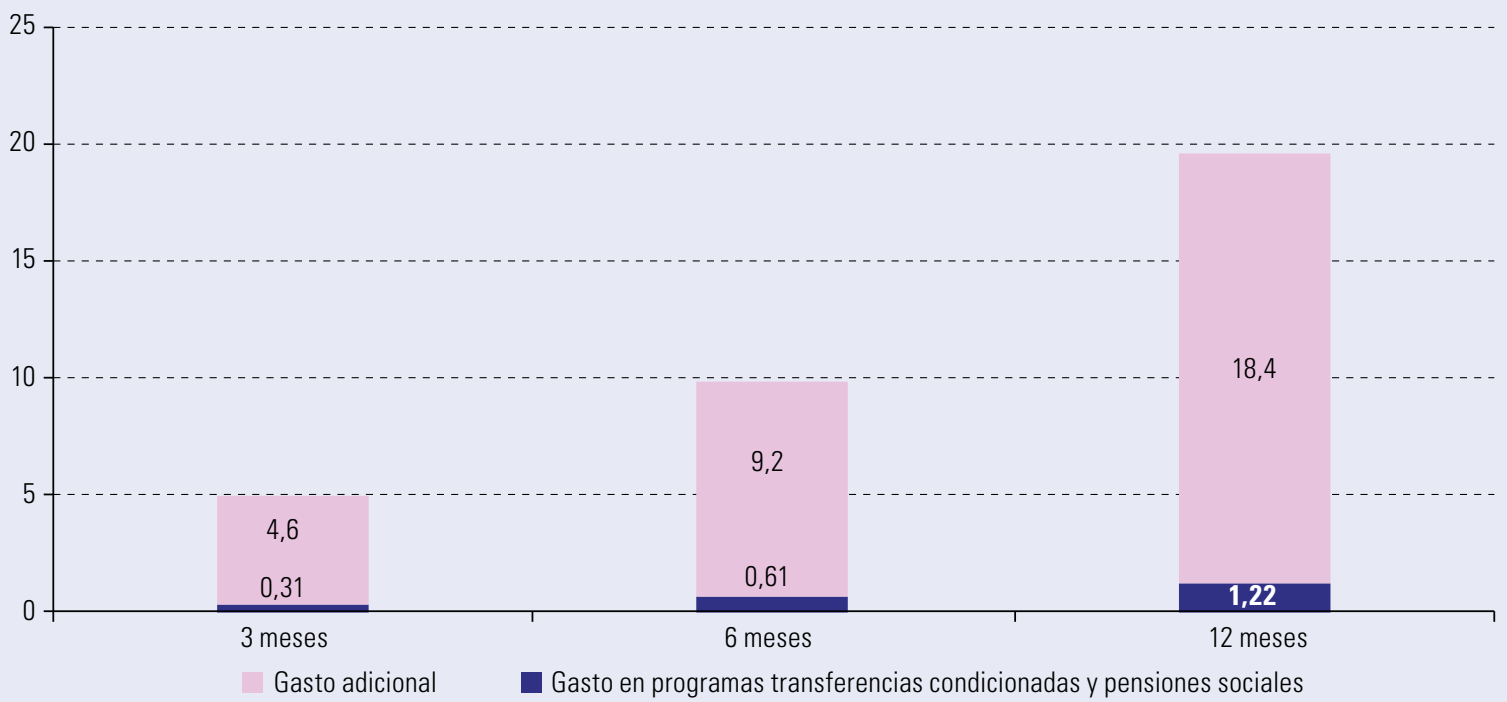

\section{B. Personas en situación de pobreza}

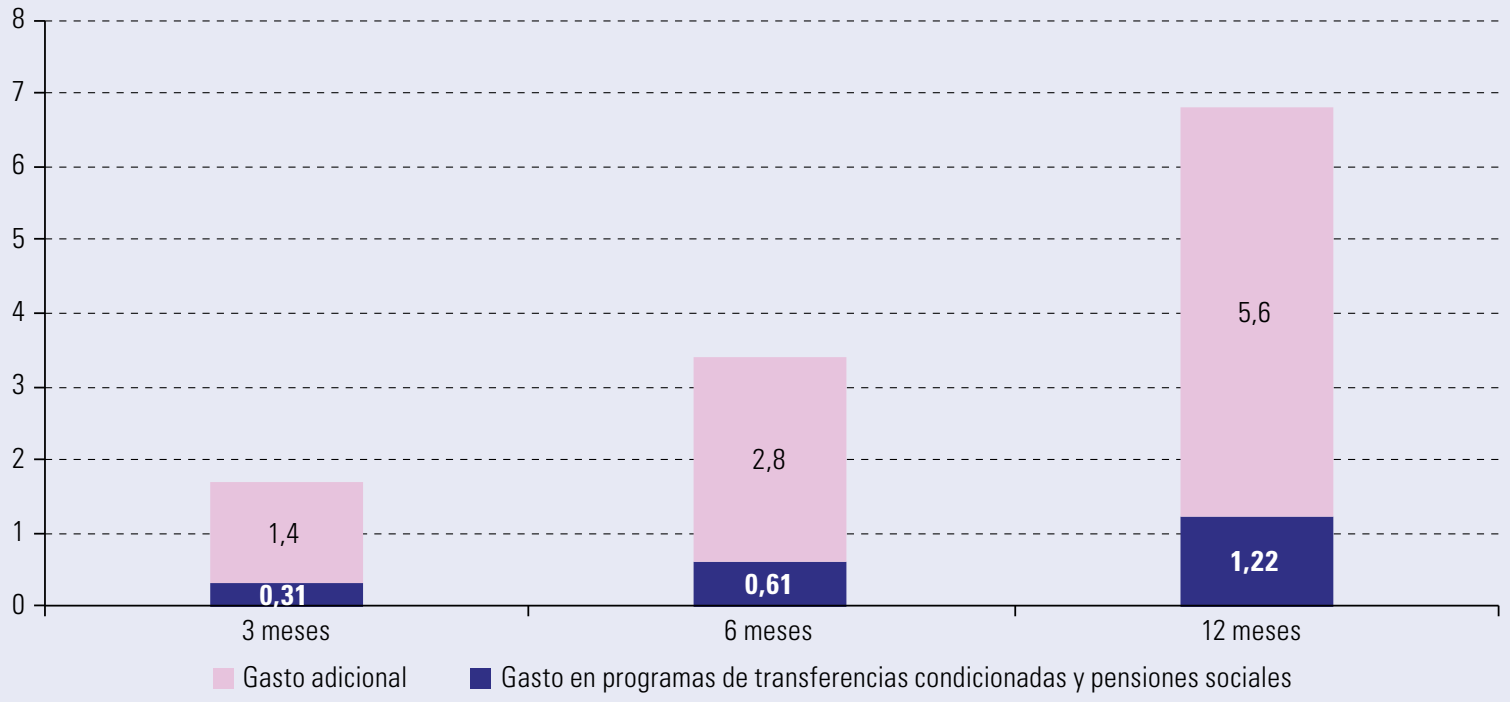

C. Niños, niñas y adolescentes de 0 a 17 años

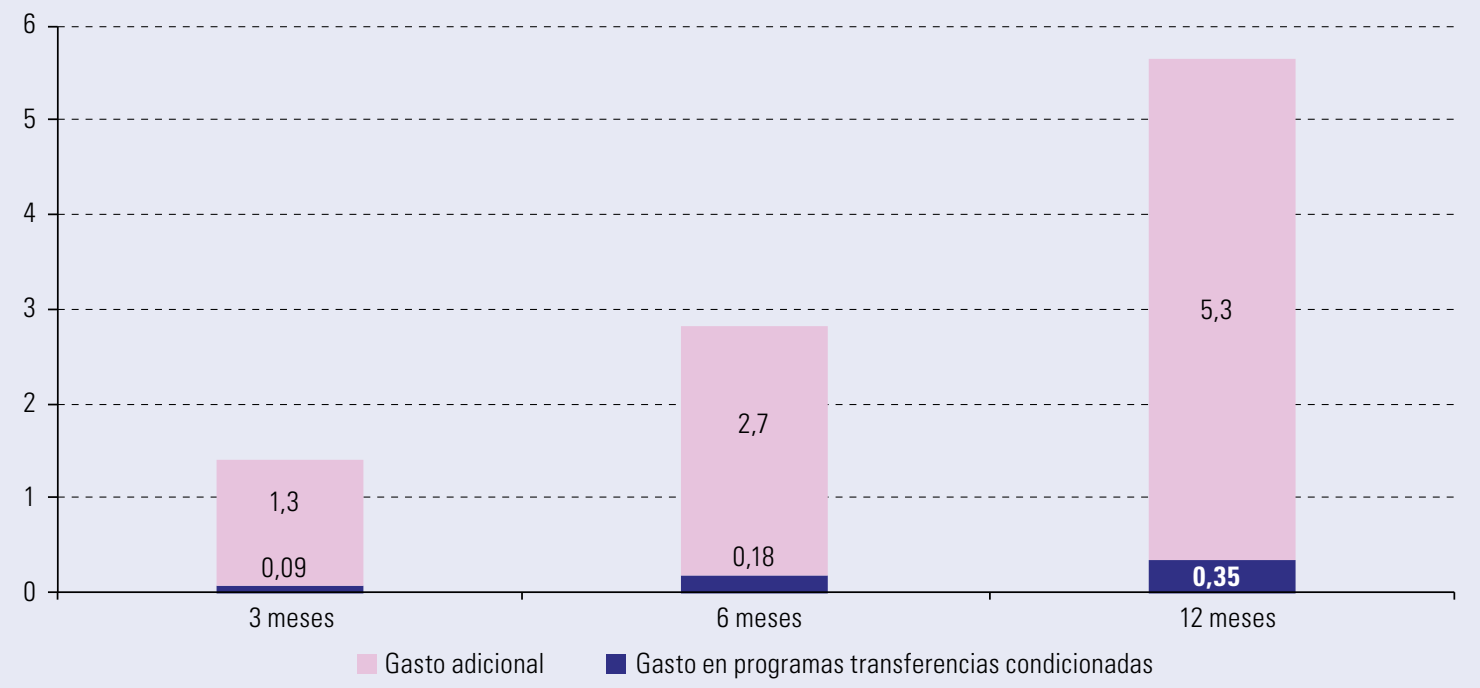


Gráfico 9 (conclusión)

D. Personas mayores de 65 años

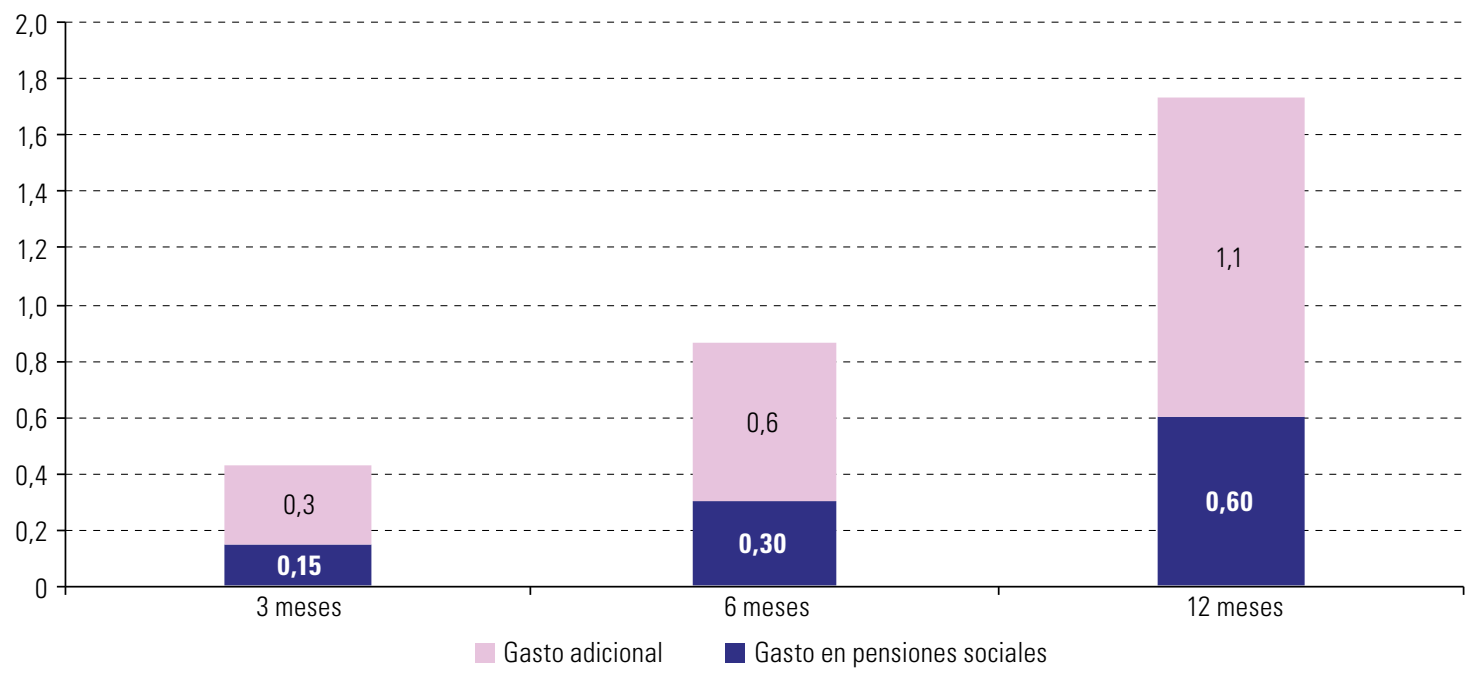

Fuente: Comisión Económica para América Latina y el Caribe (CEPAL).

a Los países considerados son: Argentina, Bolivia (Estado Plurinacional de), Brasil, Chile, Colombia, Costa Rica, Ecuador, El Salvador, Guatemala, Honduras, México, Nicaragua, Panamá, Paraguay, Perú, República Dominicana, Uruguay y Venezuela (República Bolivariana de).

• Estimación basada en una caída del 5,3\% del PIB en 2020 y considerando una población pobre de 214,7 millones en el mismo año. No se toman en cuenta los costos administrativos necesarios para efectuar las transferencias.

\section{E. El desafío es fortalecer el Estado de bienestar para evitar otra década perdida}

- Desde 2014, antes de la pandemia, la región vivía un proceso de deterioro de la situación social en términos de pobreza y pobreza extrema, y un menor ritmo de reducción de la desigualdad.

- Ante las grandes brechas históricas que la pandemia ha agravado, la CEPAL reitera que es el momento de implementar políticas universales, redistributivas y solidarias con enfoque de derechos, para no dejar a nadie atrás.

- Generar respuestas de emergencia desde la protección social para evitar un grave deterioro en las condiciones de vida es ineludible desde una perspectiva de derechos y bienestar.

- Las respuestas en materia de protección social deben articular las medidas de corto plazo, necesarias para atender las manifestaciones más agudas de la emergencia, con otras de mediano y largo plazo, orientadas a garantizar el ejercicio de los derechos de las personas mediante el fortalecimiento del Estado de bienestar y la provisión universal de protección social. Esto requiere una implementación gradual y la búsqueda de mecanismos de financiamiento sostenibles.

- En el corto plazo, la protección social, al asegurar los ingresos y el consumo en los hogares, contrarresta la pérdida de fuentes de ingresos laborales y sostiene la demanda, al tiempo que facilita el acceso a la salud. Las acciones clave son el establecimiento de una garantía universal de ingresos, especialmente para los trabajadores informales y precarios, así como el acceso universal a las pruebas y a la atención médica a todos quienes lo necesiten, a los servicios básicos y a la vivienda, a la alimentación adecuada y a la educación en el caso de niños, niñas, adolescentes y personas jóvenes.

- En el mediano y largo plazo, la protección social es una política central para la reducción de las desigualdades, el avance hacia la inclusión social y el crecimiento inclusivo, y, por ende, para la cohesión social. Será crucial consolidar sistemas de protección social universales, que incluyan la salud universal, basados en un enfoque de derechos y sensibles a las diferencias, y desarrollar estrategias de inclusión laboral en el período de la recuperación. Estos sistemas permiten identificar y responder a los impactos de la crisis en el empleo y las condiciones de vida de las personas, y atender la situación diferenciada que enfrentan diversas poblaciones, con atención 
oportuna a los trabajadores informales, a los grupos etarios más vulnerables, a los habitantes de áreas rurales y remotas, a los pueblos indígenas y las poblaciones afrodescendientes, a las personas con discapacidad y a los migrantes.

- Definir un conjunto de garantías universales para el bienestar social en función de las capacidades nacionales, en línea con la Agenda 2030 para el Desarrollo Sostenible y la Recomendación sobre los Pisos de Protección Social, 2012 (núm. 202) de la OIT, es esencial para el desarrollo sostenible y la estabilidad política.

- La Agenda Regional de Desarrollo Social Inclusivo aprobada en 2019 ofrece líneas de acción para alcanzar ese objetivo. Incluye propuestas para avanzar en la garantía universal de un nivel de ingresos básico y evaluar la posibilidad de incorporar gradualmente en los sistemas de protección social de los países una transferencia universal para la infancia y un ingreso básico de ciudadanía. Propone también el fortalecimiento de la institucionalidad social para implementar políticas sociales de calidad. Para la planificación, diseño e implementación de medidas de protección social es importante proteger el gasto público social y contar con sistemas de información, seguimiento y evaluación de las prestaciones sociales, incluidos registros de la población destinataria o potencialmente destinataria que sean lo más amplios y actualizados posible.

- Construir el Estado de bienestar y sistemas de protección social universal es clave para evitar otra década perdida. La crisis financiera internacional de 2008 mostró la importancia del gasto público social contracíclico y de las políticas sociales orientadas a moderar los efectos de la crisis en las economías reales y frenar el aumento del desempleo y la pobreza. En cambio, la crisis de la deuda de los años ochenta llevó a incrementos muy significativos de los niveles de pobreza. La región demoró 25 años en retornar a los niveles de pobreza previos a la crisis. Revisar estas experiencias es importante pues el aumento de la pobreza proyectado por la CEPAL para 2020 implica un retroceso de 13 años (véase el gráfico 10).

Gráfico 10 América Latina (18 paísesª): PIB per cápita e incidencia de la pobreza, 1980-2020 b

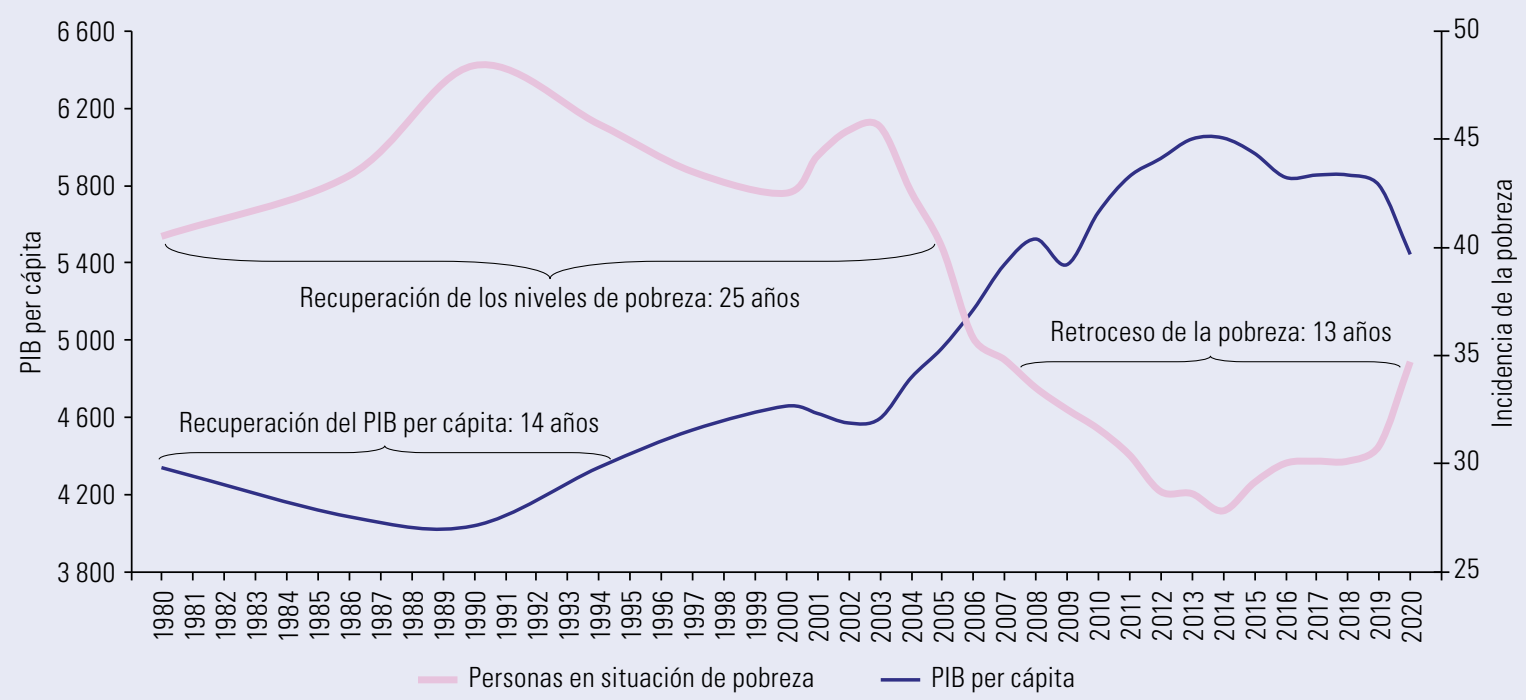

Fuente: Comisión Económica para América Latina y el Caribe (CEPAL), sobre la base del Banco de Datos de Encuestas de Hogares (BADEHOG).

a Los países considerados son: Argentina, Bolivia (Estado Plurinacional de), Brasil, Chile, Colombia, Costa Rica, Ecuador, El Salvador, Guatemala, Honduras, México, Nicaragua, Panamá, Paraguay, Perú, República Dominicana, Uruguay y Venezuela (República Bolivariana de).

${ }^{b}$ Las cifras de 2019 son datos preliminares; las cifras de 2020 son proyecciones.

- Un elemento central en la construcción de un Estado de bienestar es el derecho a la salud. Superar la actual fragmentación, jerarquización y mercantilización de los sistemas de salud será una de las enseñanzas que dejará la pandemia. Además, es urgente contar con políticas de mayor alcance y profundidad para enfrentar los determinantes sociales de la salud $y$, en particular, los requerimientos de salud alimentaria y nutricional. 
- La crisis puede profundizar expresiones de malestar, desconfianza y desafección democrática, lo que constituye un riesgo importante para la cohesión social. Urge avanzar en un pacto social centrado en el bienestar y los derechos en las distintas etapas del ciclo de vida para enfrentar los impactos de la crisis, planteando una lógica de protección colectiva e igualdad, con respuestas solidarias en los costos y el financiamiento, lo que requiere nuevos pactos fiscales.

- La pandemia ha puesto al descubierto no solo las limitaciones estructurales del modelo económico vigente, sino también las fallas e insuficiencias de los sistemas de protección social y de los regímenes de bienestar en general. Avanzar hacia el trabajo decente, fomentar la corresponsabilidad en los cuidados entre el Estado, el mercado y las familias, y promover el acceso universal a la protección social, asegurando el acceso a sistemas de salud pública de calidad, es imprescindible para proteger las condiciones de vida de toda la población.

- Para salir de la crisis es necesario repensar el modelo de desarrollo y consolidar las dimensiones económicas, sociales y ambientales del desarrollo sostenible, sin dejar a nadie atrás, como se plantea en la Agenda 2030 para el Desarrollo Sostenible.

\section{Bibliografía}

CEPAL (Comisión Económica para América Latina y el Caribe) (2020a), "América Latina y el Caribe ante la pandemia del COVID-19: efectos económicos y sociales", Informe Especial COVID-19, № 1, 3 de abril [en línea] https://repositorio.cepal.org/bitstream/handle/11362/45337/4/S2000264_es.pdf.

_ (2020b), "Dimensionar los efectos del COVID-19 para pensar en la reactivación", abril [en línea] https:// www.cepal.org/es/publicaciones/45445-dimensionar-efectos-covid-19-pensar-la-reactivacion.

Durán-Valverde, F. y otros (2019), "Measuring financing gaps in social protection for achieving SDG target 1.3: global estimates and strategies for developing countries", EES Working Paper, №73, Ginebra, Organización Internacional del Trabajo (OIT).

Folha de S. Paulo (2020), "Metade da população poderá ter de receber auxílio, diz estudo" [en línea] https://www1.folha.uol.com.br/mercado/2020/05/metade-da-populacao-podera-ter-de-receber-auxiliodiz-estudo.shtml.

Ministerio de Salud (2020), Boletim Epidemiológico Especial COE-COVID19, № 14, Brasilia, 26 de abril.

OIT (Organización Internacional del Trabajo) (2018), Mujeres y hombres en la economía informal: un panorama estadístico, tercera edición, Ginebra.

UNESCO (Organización de las Naciones Unidas para la Educación, la Ciencia y la Cultura) (2020), “Interrupción educativa y respuesta al COVID-19" [en línea] https://es.unesco.org/covid19/educationresponse.

UNICEF (Fondo de las Naciones Unidas para la Infancia) (2020), “La pandemia de COVID-19 podría devastar la vida de las poblaciones de refugiados, migrantes y desplazados internos si no se toman medidas internacionales urgentes", 1 de abril [en línea] https://www.unicef.org/es/comunicados-prensa/covid-19podria-devastar-vida-de-refugiados-migrantes-desplazados. 


\section{Anexo}

Cuadro A1 | América Latina y el Caribe (29 países): países que han anunciado medidas de protección social para la población en situación de pobreza y vulnerabilidad para enfrentar los efectos de la pandemia del COVID-19, por tipo de medida, al 24 de abril de 2020

\begin{tabular}{|c|c|c|c|c|c|c|c|}
\hline & $\begin{array}{c}\text { Transferencias } \\
\text { monetarias }\end{array}$ & $\begin{array}{l}\text { Anticipo de } \\
\text { entrega de } \\
\text { programas de } \\
\text { transferencias } \\
\text { existentes }\end{array}$ & $\begin{array}{l}\text { Aumento de } \\
\text { la cobertura } \\
\text { poblacional de } \\
\text { transferencias } \\
\text { existentes }\end{array}$ & $\begin{array}{l}\text { Aumento del } \\
\text { monto de } \\
\text { transferencias } \\
\text { monetarias } \\
\text { existentes }\end{array}$ & $\begin{array}{c}\text { Nueva } \\
\text { transferencia } \\
\text { monetaria }\end{array}$ & $\begin{array}{l}\text { Entrega de } \\
\text { alimentos y } \\
\text { medicamentos }\end{array}$ & $\begin{array}{l}\text { Servicios } \\
\text { básicos }\end{array}$ \\
\hline \multicolumn{8}{|l|}{ Antigua y Barbuda } \\
\hline \multicolumn{8}{|l|}{ Argentina } \\
\hline \multicolumn{8}{|l|}{ Bahamas } \\
\hline \multicolumn{8}{|l|}{ Barbados } \\
\hline \multicolumn{8}{|l|}{ Belice } \\
\hline \multicolumn{8}{|l|}{$\begin{array}{l}\text { Bolivia (Estado } \\
\text { Plurinacional de) }\end{array}$} \\
\hline \multicolumn{8}{|l|}{ Brasil } \\
\hline \multicolumn{8}{|l|}{ Chile } \\
\hline \multicolumn{8}{|l|}{ Colombia } \\
\hline \multicolumn{8}{|l|}{ Costa Rica } \\
\hline \multicolumn{8}{|l|}{ Cuba } \\
\hline \multicolumn{8}{|l|}{ Ecuador } \\
\hline \multicolumn{8}{|l|}{ El Salvador } \\
\hline \multicolumn{8}{|l|}{ Granada } \\
\hline \multicolumn{8}{|l|}{ Guatemala } \\
\hline \multicolumn{8}{|l|}{ Guyana } \\
\hline \multicolumn{8}{|l|}{ Haití } \\
\hline \multicolumn{8}{|l|}{ Honduras } \\
\hline \multicolumn{8}{|l|}{ Jamaica } \\
\hline \multicolumn{8}{|l|}{ México } \\
\hline \multicolumn{8}{|l|}{ Panamá } \\
\hline \multicolumn{8}{|l|}{ Paraguay } \\
\hline \multicolumn{8}{|l|}{ Perú } \\
\hline \multicolumn{8}{|l|}{ República Dominicana } \\
\hline \multicolumn{8}{|l|}{$\begin{array}{l}\text { San Vicente y } \\
\text { las Granadinas }\end{array}$} \\
\hline \multicolumn{8}{|l|}{ Santa Lucía } \\
\hline \multicolumn{8}{|l|}{ Trinidad y Tabago } \\
\hline \multicolumn{8}{|l|}{ Uruguay } \\
\hline $\begin{array}{l}\text { Venezuela (República } \\
\text { Bolivariana de) }\end{array}$ & & & & & & & \\
\hline
\end{tabular}

Fuente: Comisión Económica para América Latina y el Caribe (CEPAL).

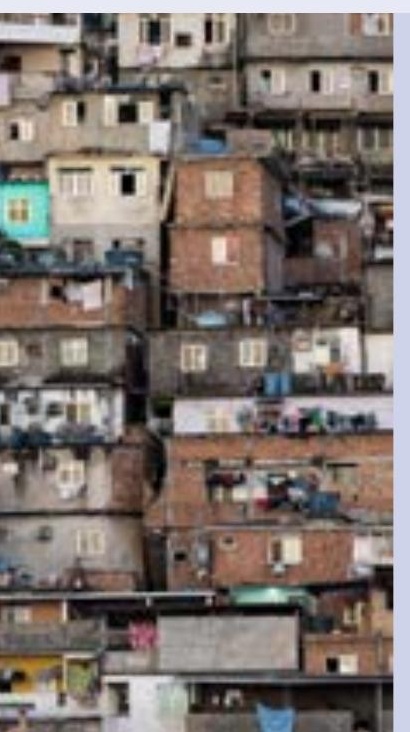

Este Informe Especial es el tercero de una serie que elaborará la Comisión Económica para América Latina y el Caribe (CEPAL) sobre la evolución y los efectos de la pandemia del COVID-19 en América Latina y el Caribe. Sus análisis económicos y sociales se actualizarán a medida que surja información relevante. La Secretaria Ejecutiva de la CEPAL, Alicia Bárcena, dirige la elaboración de este Informe, con el apoyo técnico de la Oficina del Secretario Ejecutivo Adjunto, Mario Cimoli, las Divisiones sustantivas encargadas de los temas que aquí se tratan, y las sedes subregionales y oficinas nacionales de la CEPAL.

Copyright (C) Naciones Unidas, 2020

\footnotetext{
C 1 Economic Commission for Latin America and the Caribbean (ECLAC) www.cepal.org
} 